\title{
DE ENMIENDAS HOMOGÉNEAS, LEYES HETEROGÉNEAS Y PRECEPTOS INTRUSOS. ¿ES CONTRADICTORIA LA NUEVA DOCTRINA DEL TRIBUNAL CONSTITUCIONAL SOBRE LA ELABORACIÓN DE LAS LEYES?
}

\author{
PIEDAD GARCÍA-ESCUDERO MÁRQUEZ \\ CATEDRÁtica de DERECHO CONSTITUCIONAL \\ UNIVERSIDAD COMPLUTENSE DE MADRID
}

SUMARIO

I. Introducción. El contenido de las leyes debe ser homogéneo.

II. Homogeneidad de las enmiendas con el texto enmendado.

III. Leyes de contenido heterogéneo.

IV. Conclusión.

\section{INTRODUCCIÓN. EL CONTENIDO DE LAS LEYES DEBE SER HOMOGÉNEO}

En un relativamente corto espacio de tiempo, el Tribunal Constitucional ha dictado cierto número de sentencias que inciden sobre la técnica normativa ${ }^{1}$ y otras de importancia para el Derecho parlamentario ${ }^{2}$. Nos vamos a centrar en las primeras para tratar de exponer y comentar la doctrina en ellas contenida, así como nuestra posición al respecto, que pretende tener siempre presente el principio de seguridad jurídica proclamado en el artículo 9.3 de la Constitución.

El punto de partida para el examen de estas sentencias es una norma básica de técnica legislativa, según la cual el contenido de la ley debe ser homogéneo: cada ley ha de regular un único objeto material, evitando incluir materias diferentes a su objeto. Si

2 SSTC 20/2011, 27/2011, 29/2011, 57/2011, 108/2011, 192/2011, 9/2012, 88/2012, 168/2012, $183 / 2012,238 / 2012,10 / 2013$. 
fuera necesario o conveniente regular distintas materias con un mismo objeto, pueden elaborarse iniciativas legislativas distintas para su tramitación simultánea, haciendo constar la conexión entre ellas en el preámbulo. Por supuesto, hay coincidencia en que deben evitarse las leyes de modificación múltiple y las llamadas «leyes ómnibus», gravemente lesivas para la seguridad jurídica.

Como decimos, todas las reglas de técnica legislativa coinciden en que el contenido de las leyes debe ser homogéneo, regulando una sola materia y, en la medida de lo posible, regulándola por entero ${ }^{3}$. Pese a ello, como es sabido, no se exige en nuestro ordenamiento la homogeneidad en el contenido de las iniciativas legislativas. La excepción la constituyen las proposiciones de iniciativa popular y algún Reglamento de Asamblea Legislativa de Comunidad Autónoma, como el artículo 101.1 del Reglamento del Parlamento de Cataluña de 2005, que exige que los proyectos y proposiciones de ley tengan un objeto material determinado y homogéneo. La Ley Orgánica 3/1984, de 26 de marzo, reguladora de la iniciativa legislativa popular, establece como causa de inadmisión a trámite «el hecho de que el texto de la proposición verse sobre materias manifiestamente distintas y carentes de homogeneidad entre sí» (art. 5.2 c) ${ }^{4}$.

Los Reglamentos de las Cámaras tampoco requieren que la homogeneidad se mantenga a lo largo de la tramitación parlamentaria, exigiendo que las enmiendas se limiten a la materia objeto del proyecto o proposición. Hemos defendido ${ }^{5}$, no obstante, que la iniciativa legislativa, impulsora del procedimiento legislativo, efectúa una determinación material de lo que constituye el objeto de la regulación propuesta y hasta de su sentido y orientación, de tal manera que las enmiendas que introduzcan modificaciones, supresiones o adiciones completan la determinación de aquellos, haciéndola definitiva. Sin embargo, hasta hace muy poco tiempo, ningún control se realizaba en las Cortes Generales sobre el contenido de las enmiendas y su adecuación al objeto de la ley, y aun después de la STC 119/2011 este control es escaso e insuficiente.

3 El apartado 3 de las Directrices de técnica normativa, aprobadas por Acuerdo del Consejo de Ministros de 22 de julio de 2005, declara: "Único objeto. En la medida de lo posible, en una misma disposición deberá regularse un único objeto, todo el contenido del objeto y, si procede, los aspectos que guarden directa relación con él. (...)». El Consejo de Estado ha denunciado más de una vez la incorrección de la técnica de introducir en una ley modificaciones que afectan a materias diferentes. «La dispersión dificulta la aplicación de las normas jurídicas, que tienen como destinatarios principales, no sólo a autoridades, funcionarios y profesionales del Derecho, sino también a los propios ciudadanos. Por eso, ha aconsejado en diversas ocasiones al órgano proponente segregar del anteproyecto remitido a consulta todas aquellas materias ajenas a su objeto principal, mientras que le mereció un juicio positivo la vocación de generalidad y de globalidad que presidía un determinado proyecto, así como el hecho de que se respetase la «sedes materiae» de cada institución y no se entrase a regular otras materias conexas pero claramente diferenciadas (Dictamen de 1 de octubre de 1998)» (F. RUBIO LLORENTE, «El papel del Consejo de Estado en el control de la calidad técnica de las normas», Revista española de la función consultiva, $\mathrm{n}^{\circ}$ 6, 2006, págs. 33-34).

4 Con anterioridad a la reforma introducida por la Ley Orgánica 4/2006, la inadmisión se producía cuando el texto de la proposición versara sobre «sobre materias diversas carentes de homogeneidad entre sí». La redacción de este apartado fue quizá el tema que levantó mayor polémica durante el debate de la LOILP, señala P. BIGLINO CAMPOS («La iniciativa legislativa popular en el ordenamiento jurídico estatal», en REDC, $\mathrm{n}^{\circ} 19,1987$, pág 116), en la medida en que varios grupos parlamentarios consideraban que su configuración en el proyecto de ley reconocía a la Mesa del Congreso de los Diputados un poder excesivamente discrecional.

5 P. GARCÍA-ESCUDERO MÁRQUEZ, El procedimiento legislativo ordinario en las Cortes Generales, CEPC, Madrid, 2006, págs. 257 y ss. 
En las recientes sentencias que comentaremos, el Tribunal Constitucional se ha ocupado de la homogeneidad en las enmiendas y en las iniciativas, con resultados distintos. Vamos a examinar los dos temas por separado, en orden tal vez inverso al que debiera seguir un criterio lógico, por respetar la cronología de los pronunciamientos del Alto Tribunal.

\section{HOMOGENEIDAD DE LAS ENMIENDAS CON EL TEXTO ENMENDADO}

\section{Derecho comparado}

Como veremos a continuación, hasta la sentencia 119/2011, sin perjuicio de algún auto que daba por supuesta la homogeneidad y congruencia de las enmiendas con el texto enmendado ${ }^{6}$, el Tribunal ha relegado en general, en defecto de norma imperativa, la cuestión de las enmiendas no homogéneas o incongruentes al ámbito de la correcta técnica legislativa. No obstante, hemos abogado por una regulación reglamentaria que impida el perjuicio que en la seguridad jurídica provoca la introducción de preceptos «intrusos».

Esta regulación se ha introducido ya en alguna reforma de Reglamento de Asamblea autonómica. Así, el artículo 107.2 del Reglamento del Parlamento de Cataluña de 22 de diciembre de 2005 establece que en las enmiendas de modificación y adición «la enmienda debe contener el texto concreto que se propone como modificación o como adición, que debe ser congruente con el objeto material de la iniciativa legislativa» ${ }^{7}$.

6 El ATC 275/1993 señala que con la presentación de tales enmiendas parciales, incompatibles o incoherentes con el marco fijado para el Pleno, se ignora «que la superación de una proposición del debate de toma en consideración supone ya la realización de ese trámite parlamentario, que no puede, en consecuencia, ser reabierto». En el mismo sentido, el auto 118/1999, a partir de los razonamientos contenidos en la sentencia 23/1990, se refiere a las enmiendas al articulado: «Esta conexión u homogeneidad de objeto con el texto enmendado resulta también exigible a las enmiendas parciales o al articulado, las cuales han de ser además congruentes con aquél, en cuanto que, superado por un proyecto de ley el debate de totalidad o por una proposición de ley el debate de toma en consideración, la iniciativa es aceptada por la Cámara como objeto de deliberación y su oportunidad, principios y espíritu no pueden ser cuestionados o alterados por las enmiendas al articulado, los cuales únicamente pueden cuestionarse a través de las enmiendas a la totalidad, si de un proyecto de ley se trata o en el debate de toma en consideración, en el caso de las proposiciones de ley, como así resulta, por otra parte, de las previsiones del Reglamento de la Asamblea Regional de Cantabria (arts. 106.3 y 116.4 y 5 , respectivamente)». Se ha señalado cómo este auto, dictado en recurso de amparo contra la decisión de la Mesa de la Asamblea Regional de Cantabria que inadmite dos enmiendas al Proyecto de Ley de Medidas Fiscales y Administrativas por no guardar relación de congruencia con el proyecto de ley que pretendían enmendar, es muestra de la oscilación doctrinal del Tribunal Constitucional, o, por decirlo de otra manera, del distinto enfoque que adopta en los recursos de inconstitucionalidad sobre enmiendas del Senado (enfoque que podríamos llamar macroconstitucional o institucional) y en los recursos de amparo (enfoque microconstitucional o de los derechos de los parlamentarios). Véase en el apartado siguiente el resumen de la doctrina anterior del Tribunal Constitucional.

7 Y continúa: «También pueden proponerse enmiendas de mejora formal de la iniciativa, de conformidad con las normas de técnica legislativa». 
También en Derecho comparado existen manifestaciones del requisito de homogeneidad, referido tanto a las iniciativas legislativas como a las enmiendas ${ }^{8}$ : el principle of relevancy aplicado en la Cámara de los Comunes, la exigencia de lien o vinculación material en Francia, que evite el cavalier legislatif) (disposición extraña a la norma, tan frecuente en nuestras leyes), o el Sachzusammenhang en el Bundestag ${ }^{10}$.

Encontramos confirmación en el ámbito constitucional de la relevancia del principio en la reforma de la Constitución francesa de 1958 por la Ley constitucional de 23 de julio de 2008: el nuevo artículo 45 exige la existencia de un lien o vínculo, aun indirecto (même indirect) de las enmiendas con el texto inicial para ser admisibles en primera lectura ${ }^{11}$.

Con anterioridad, ya el artículo 74.5 de la Constitución de Grecia impedía que pueda someterse a debate «proyecto o proposición de ley alguno que contenga disposi-

8 Puede verse un repaso de la cuestión en Derecho comparado, en A. M. ${ }^{a}$ REDONDO GARCÍA, El derecho de enmienda en los procedimientos legislativos de las Cortes Generales, Congreso de los Diputados, Madrid, 2001, págs. 126-135.

9 Véase B. BAUFUME, Le droit d'amendement et la Constitution sous la Cinquième République, Librairie générale de droit et de jurisprudence, París, 1993, pág. 253; G. Carcassonne, ( À propos du droit d'amendement: les errements du Conseil constitutionnel», en Pouvoirs, n 41, 1987, págs. 163-170; y L. Favoreu y L. Philip, Les grandes décisions du Conseil constitutionnel, $8^{\mathrm{a}}$ ed., Dalloz, París, 1995, págs 732-740. Entre nosotros, recoge la jurisprudencia del Conseil constitutionnel A. DÍAZ-ROMERAL GÓMEZ, «Notas en torno a las leyes de objeto diverso. Elaboración parlamentaria y jurisprudencia constitucional», en Cuadernos de Derecho Público, $\mathrm{n}^{\circ}$ 6, 1999, págs. 144 y ss. Para adaptarse a ella, el Reglamento del Senado francés introdujo en 1990 la necesidad de que la enmienda presentada como adición de un artículo «no esté desprovista de todo vínculo con el objeto del texto en discusión» (artículo 48.3). También prohíbe los cavaliers legislatifs el Reglamento de la Asamblea Nacional (art. 98.5). A. DELCAMP («Le Conseil Constitutionnel et le Parlement», Revue française de Droit Constitutionnel, $\mathrm{n}^{\circ} 57,2003$, págs. 65 y ss.) describe la evolución posterior de la jurisprudencia constitucional (a partir de la decisión 2001-45 DC, de 19 de junio), que tiene en cuenta que el derecho de enmienda se ha convertido en el instrumento principal de obstrucción parlamentaria. Como puede verse en el texto, la exigencia de lien ha alcanzado rango constitucional en 2008.

10 Para la opinión de la doctrina en Italia, véase F. CUOCOLO, Saggio sull' iniziativa legislativa, Giuffrè, Milán, 1971, pág. 31. La presentación del proyecto o la toma en consideración de la proposición de ley, además de poner en marcha el procedimiento, tiene por efecto la delimitación material del texto que va a tramitarse, de modo que se identifica la materia sobre la cual la Cámara está llamada a deliberar. Con ello también se precisan los intereses para los que se requiere satisfacción por el legislador. No obstante, afirma este autor, el saississement de la asamblea no puede ir más allá de la mera indicación de una cierta materia regulable de un cierto modo por la ley, pero quedando libre el Parlamento sobre el an y el quomodo de la efectiva medida a adoptar («Iniziativa legislativa», Enciclopedia del Diritto, vol. 21, Giuffrè, Milán, 1971, pág. 611). En sentido mucho más restrictivo sobre la amplitud de la libertad de la Cámara, sobre todo en cuanto a la identificación de la materia sobre la que legislar, S. GALEOTTI (Contributo alla teoría del procedimento legislativo, Giuffrè, Milán, 1957, págs. 244 y ss): con la propuesta legislativa se produce la fijación de la «materia del legiferare», y por tanto de los límites dentro de los cuales se mueven la facultad de enmienda y los mismos poderes de deliberación final. El objeto o contenido originario podrá ser enmendado y perfeccionado para hacerlo más aceptable como contenido de la ley, facilitando la aprobación final; pero no podrá ser subvertido, mutado y sustituido por otro que no presente ninguna conexión sustancial con la propuesta de origen (págs. 253-254).

Pueden verse los arts. 89.1 del Reglamento de la Camera y 97.1 del Reglamento del Senado (inadmisión de enmiendas ajenas al objeto del debate).

11 La exigencia de lien o conexión material entre proyecto y enmienda, que impide los cavaliers législatifs, se debe a la nueva determinación del texto legislativo que se debate en sesión plenaria, que pasa a ser no ya el proyecto del Gobierno sino el aprobado por la comisión. Puede verse al respecto P. BON, «La Constitución de la Quinta República cumple 50 años», REDC, n. ${ }^{\circ}$ 85, 2009, pág. 69. 
ciones sin relación con su objeto principal», estableciendo asimismo que «no se someterá a discusión ninguna disposición adicional o enmienda si no tuviera relación con el objeto principal del proyecto o de la proposición de ley», correspondiendo a la Cámara resolver en caso de discrepancia.

También la Constitución de Colombia, en su artículo 158, dispone que «todo proyecto de ley debe referirse a una misma materia y serán inadmisibles las disposiciones o modificaciones que no se relacionen con ella $^{12}{ }$, lo que ha sido objeto de interpretación por la Corte Constitucional en varios pronunciamientos ${ }^{13}$.

\section{Doctrina anterior del Tribunal Constitucional}

Hasta ahora, la doctrina del Alto Tribunal podía ser calificada de oscilante — por más que haya querido justificar su coherencia en la sentencia 119/2011 — en cuanto a la necesidad o no de conexión material de las enmiendas con el texto legislativo enmendado. Hemos mantenido, pese a ello, la necesidad de que las enmiendas respeten los principios citados de homogeneidad y congruencia ${ }^{14}$, muy en particular en el procedimiento agravado de reforma constitucional ${ }^{15}$.

12 «El Presidente de la respectiva comisión rechazará las iniciativas que no se avengan con este precepto, pero sus decisiones serán apelables ante la misma comisión».

13 Por ejemplo, ha señalado que el principio de unidad de materia que surge de los artículos 158 y 169 debe ser observado estrictamente por el legislador ordinario, «con el objeto de evitar que en las leyes, sin el debido estudio y de modo sorpresivo, aparezcan normas ajenas al tema del cual se ocupan». Esos perentorios mandatos del constituyente están encaminados a lograr que la tarea legislativa se concentre en puntos claramente definidos por el mismo Congreso, con el objeto de brindar a los destinatarios de las leyes seguridad jurídica y adecuado marco para la interpretación y aplicación de las mismas. En la sentencia C-290/2000, la Corte afirma, recordando la sentencia 568/97: «Adicionalmente, las diferentes disposiciones contenidas en el cuerpo de una ley deben guardar coherencia y resultar de cierta manera relacionadas entre sí, de tal modo que quienes estén llamados a cumplirlas puedan consultarlas acudiendo a su clasificación por el tema al que se refieren, bajo el entendido de que normas aisladas no se encontrarán recogidas dentro de leyes que regulan otros tópicos ajenos a su contenido particular. Es por ello que la Constitución da importancia a la congruencia entre el título de las leyes y su contenido». «El principio de unidad de materia ... facilita su cumplimiento, la identificación de sus destinatarios potenciales y la precisión de los comportamientos prescritos, ...todo lo cual redunda en la cabal observancia de la seguridad jurídica tan cara a los postulados del Estado social de Derecho... Principio de unidad de materia que no puede rebasar su finalidad, de modo que solamente aquellos apartes, segmentos o proposiciones de una ley respecto de los cuales, razonable y objetivamente, no sea posible establecer una relación de conexidad causal, teleológica, temática o sistemática con la materia dominante de la misma, deben rechazarse como inadmisibles si están incorporados en el proyecto o declararse inexequibles si integran el cuerpo de la ley» (sentencia C-025-1993).

14 P. GARCÍA-ESCUDERO MÁRQUEZ, El procedimiento legislativo ordinario en las Cortes Generales, cit., págs. 238 y ss.

15 Para evitar que por vía de enmienda se introduzcan modificaciones no previstas en el principio de reforma aprobado por la primera legislatura y ratificado por la segunda, que esquivaran las reglas de procedimiento establecidas por el artículo 168 de la Constitución. Recuérdese que en la tramitación de las leyes de armonización, que pueden presentar cierto paralelismo procedimental, el artículo 168.3 del Reglamento del Congreso declara no admisibles las enmiendas que impliquen contradicción con el previo pronunciamiento de la Cámara de apreciación de la necesidad. P. GARCÍA-ESCUDERO MÁRQUEZ, El procedimiento agravado de reforma de la Constitución de 1978, CEPC, Madrid, 2007, págs. 101-102. 
Es conocida la sentencia 99/1987, sobre la Ley 30/1984, de medidas para la reforma de la función pública, en la que el Tribunal afirmaba que «no existe ni en la Constitución ni en los Reglamentos de ambas Cámaras norma alguna que establezca una delimitación material entre enmienda y proposición de ley. Ni por su objeto, ni por su contenido, hay límite alguno a la facultad que los miembros de las Cámaras tienen para presentar enmiendas, exceptuadas las que, tanto para las enmiendas como para las proposiciones de ley, fijan los arts. 84 y 134.6 de la Constitución para asegurar un ámbito de acción propia al Gobierno».

Esta doctrina fue ratificada por el Pleno del Tribunal en la sentencia 194/2000, de 19 de julio, en el recurso de inconstitucionalidad contra la disposición adicional cuarta de la Ley 8/1989, de 13 de abril, de tasas y precios públicos, en que se regulaba, mediante una enmienda introducida en el Senado, el tratamiento fiscal de las diferencias de valor resultantes de la comprobación administrativa a efectos del impuesto sobre transmisiones patrimoniales. El Tribunal afirmó que los artículos 90.2 CE y 107 RS «no limitan el alcance de las enmiendas senatoriales que modifiquen el texto del proyecto enviado por el Congreso de los Diputados» ${ }^{16}$, rechazando que el procedimiento empleado hubiera restringido las facultades del Congreso.

En la sentencia 119/2011, el Tribunal justifica los dos pronunciamientos expuestos —ante supuestos similares en que el precepto impugnado había sido incluido como enmienda senatorial - en que se había tomado en consideración, por un lado, la alegación de los recurrentes de que no respondía a la finalidad concreta de la iniciativa legislativa, pero sin negar que existía una conexión material, y por otro la inexistencia de previsión expresa en el Reglamento del Senado al respecto, lo que llevaba a concluir «en defensa del amplio margen de autonomía y valoración de las Cámaras, que no cabe derivar de la Constitución la existencia de unos límites al alcance de las enmiendas senatoriales que impidan innovaciones en la finalidad de la iniciativa legislativa, de modo que la negativa a valorar la concurrencia de una conexión material u homogeneidad entre la enmienda y la iniciativa legislativa como requisito de admisibilidad de una enmienda no supondría un infracción de la legalidad parlamentaria».

Junto a estos dos pronunciamientos, el Tribunal destaca tres resoluciones dictadas en procedimientos de amparo interpuestos por la vía del artículo 42 LOTC contra decisiones de Mesas de Parlamentos autonómicos, en las que fue más proclive a reconocer la necesidad de homogeneidad de las enmiendas con las iniciativas enmendadas, confirmando la constitucionalidad de las valoraciones de las respectivas Mesas no sólo en aquellos supuestos en que el Reglamento de la Cámara lo había previsto de manera expresa (STC 23/1990, sobre el rechazo por la Mesa de las Cortes Valencianas de una enmienda de texto alternativo a un proyecto de Proposición de ley orgánica de modificación del Estatuto de Autonomía por carecer de congruencia con el texto a que iba dirigida, y ATC 275/1993, en relación con la inadmisión por la Mesa de la Junta General del Principado

16 «La tesis de los recurrentes, según la cual las enmiendas de adición formuladas en el Senado que supongan una innovación importante deben seguir el cauce legal correspondiente a los proyectos de ley puede invocar en su favor razones de corrección técnica y buena ordenación del procedimiento legislativo e incluso puede resultar más acorde con la posición constitucional atribuida al Senado en nuestro ordenamiento, pero no se deduce necesariamente del bloque de constitucionalidad» (FJ 3). 
de Asturias de 23 enmiendas a la propuesta de Proposición de ley orgánica de reforma del Estatuto de Autonomía, con fundamento en la desconexión entre el contenido de las enmiendas y el texto de la propuesta, pretendiendo en realidad una enmienda a la totalidad con texto alternativo ${ }^{17}$ ), sino también en aquellos casos en que no se establecía una concreta previsión al respecto: ATC 118/1999, sobre el rechazo por la Mesa de la Asamblea Regional de Cantabria de dos enmiendas por incongruentes con el texto que se pretendía enmendar. El auto hacía extensiva a las enmiendas parciales la jurisprudencia establecida en la STC 23/1990, sobre la exigencia de correlación material con el texto enmendado en el caso de las enmiendas a la totalidad de texto alternativo. La importancia de este auto residía en que reconocía la necesidad de concurrencia en las enmiendas de los dos requisitos de homogeneidad y congruencia que reclamaba la doctrina ${ }^{18}$.

\section{Nueva doctrina sobre el derecho de enmienda}

El caso — que habíamos calificado de llamativo e ilustrativo de lo que son las normas intrusas ${ }^{19}$ — que motivó la revisión de la doctrina del Tribunal Constitucional en la sentencia 119/2011 ${ }^{20}$ fue la inclusión de una nueva normativa penal en relación con la convocatoria de referéndums en el Senado por vía de enmienda al Proyecto de Ley Orgánica complementaria de la Ley de Arbitraje por la que se modifica la Ley Orgánica del Poder Judicial, posteriormente convertido en Ley Orgánica 20/2003, de 23 de diciembre, de modificación de la Ley Orgánica del Poder Judicial y del Código Penal. A su vez, el Proyecto de Ley Orgánica había nacido del desglose acordado por la Mesa del Congreso a partir del Proyecto de Ley de Arbitraje, al introducirse en la Comisión de Justicia e Interior una modificación de la Ley Orgánica del Poder Judicial (véase BOCG Congreso, Serie A, n. ${ }^{\circ} 175-1$, de 18 de noviembre de 2003) ${ }^{21}$.

17 «Ignorando con ello que la superación de una proposición del debate de toma en consideración supone ya la realización de ese trámite parlamentario, que no puede en consecuencia ser reabierto» (FJ 2).

18 Así, A. ARCE JANÁRIZ, «El derecho de enmienda visto por el Tribunal Constitucional», REDC, n. ${ }^{\circ} 41,1994$, pág. 163.

19 P. GARCÍA-ESCUDERO MÁRQUEZ, Técnica legislativa y seguridad jurídica: ¿ bacia el control constitucional de la calidad de las leyes?, Aranzadi-Civitas, Cizur Menor, 2010, pág. 72.

20 STC 119/2011, de 5 de julio, en el recurso de amparo avocado núm 7464-2003, promovido por 62 senadores contra el acuerdo de la Mesa del Senado de 3 de diciembre de 2003, por el que se confirma el acuerdo de 2 de diciembre de 2003, que admitió a trámite las enmiendas n. 3 y 4 presentadas por el Grupo Parlamentario Popular al Proyecto de Ley Orgánica complementaria de la Ley de Arbitraje.

21 Puede verse el debate de las enmiendas del Senado en el Pleno del Congreso en el Diario de sesiones número 307, de 18 de diciembre de 2003, págs. 16231 y ss. Todos los grupos parlamentarios, con la excepción del Popular, optaron por no participar en la votación, resultando aprobadas las enmiendas del Senado por 180 votos emitidos (179 a favor y una abstención) y con el mismo resultado la votación final de conjunto por tratarse de un proyecto de ley orgánica (pág. 16244). En el debate se citaron varios precedentes de cavaliers legislatifs, véase especialmente págs. 16239 y 16243.

Parecía que el Tribunal no enjuiciaría estos defectos, pues por Auto 311/2007 declaraba la extinción del recurso de inconstitucionalidad presentado por el Parlamento de Cataluña contra el artículo 2 de esta Ley, por desaparición sobrevenida de su objeto, al haber sido derogados por Ley Orgánica 2/2005, de 22 de junio, los artículos del Código Penal incorporados por el precepto citado y no concurrir razón alguna de interés público ni afectación al de los particulares que aconsejaran la prosecución del proceso hasta su finalización por sentencia. 
Este ejemplo nos muestra precisamente uno de los sectores del ordenamiento, la normativa penal, en el que la técnica legislativa ha de ser especialmente cuidada, pues los defectos que inciden en la claridad de las normas o de su aplicación lesionan especialmente la seguridad jurídica, pero también las exigencias del artículo 25 de la Constitución.

En la importante sentencia 119/2011, el recurso de amparo fue avocado por el Pleno del Tribunal Constitucional de conformidad con el artículo 13 de la LOTC, según declara expresamente (FJ 6) para revisar la jurisprudencia sentada por el Pleno en las sentencias 99/1987 y 194/2000 y clarificarla a la vista de la sentencia 23/1990 y de los autos 275/1993 y 118/1999, clarificación y revisión especialmente convenientes al tratarse de resoluciones de distinta naturaleza y dictadas tanto en recursos de inconstitucionalidad como en recursos de amparo.

A los efectos que aquí nos interesan, no referidos exclusivamente a las enmiendas del Senado (a las que, dada la naturaleza del recurso, debía circunscribirse la doctrina contenida en la sentencia), destaquemos el resumen siguiente (FJ 6): «incluso en los supuestos en que el Reglamento de la Cámara legislativa correspondiente, como es el del Senado, guarde silencio sobre la posibilidad de que la Mesa respectiva verifique un control de homogeneidad entre las enmiendas presentadas y la iniciativa legislativa a enmendar, esta exigencia se deriva del carácter subsidiario que toda enmienda tiene respecto al texto enmendado, de la lógica de la tramitación legislativa y de una lectura conjunta de las previsiones constitucionales sobre el proceso legislativo», no considerando el Tribunal novedosa la conclusión de que la Constitución impone, aun implícitamente, la existencia de determinados límites materiales en la actividad legislativa, por haberse aplicado con anterioridad a las leyes de presupuestos.

El Tribunal matiza, no obstante, su doctrina, reconociendo un amplio margen de apreciación a las Mesas de las Cámaras para determinar la existencia de conexión material entre enmienda e iniciativa, pero esta tarea «cuando lo que se plantea es precisamente una falta absoluta de conexión, no puede reducirse a una simple decisión injustificada sino a una valoración motivada, aunque sea sucintamente, sobre la existencia o no de dicha conexión mínima» ${ }^{22}$. Esta valoración, por otra parte, debe hacerse en el seno del procedimiento legislativo, en el que las dos Cámaras no están en la misma posición, por lo que «la aplicación de esta doctrina en cada caso no puede hacerse sin valorar que el Congreso y el Senado no actúan en el mismo momento ni son exactamente las mismas sus facultades formales». Para supuestos de urgencia, el Tribunal recuerda que existe la posibilidad de acudir a otros mecanismos, como el decreto ley o los procedimientos de urgencia o lectura única ${ }^{23}$.

22 «... pues sólo cuando sea evidente y manifiesto que no existe tal conexión deberá rechazarse la enmienda, puesto que en tal caso se pervertiría la auténtica naturaleza del derecho de enmienda, ya que habría pasado a convertirse en una nueva iniciativa legislativa» (FJ7).

23 «Dicho de otra forma, aceptar el ejercicio del derecho de enmienda como mecanismo paliativo o sustitutivo de las insuficiencias que pudieran tener los procedimientos legislativos supondría tanto como hacer caso omiso de la voluntad del constituyente» que ya ha determinado los instrumentos con los que hacer frente a las urgencias legislativas. «Desatender los límites constitucionales bajo el paraguas de la urgencia normativa no deja de ser una lesión constitucional por mucho que pueda parecer conveniente coyunturalmente. Una buena política legislativa puede evitarlo y cuando excepcionalmente no sea posible debe asumir el coste democrático que pueda tener pero no forzar la Constitución» (FJ 7). 
El Tribunal cierra su razonamiento destacando que el derecho de enmienda de los parlamentarios no es un mero derecho reglamentario sino un auténtico contenido central de su derecho de participación del artículo 23.2 de la Constitución (FJ 8), que se ve lesionado si el debate se articula de forma que la introducción de más enmiendas haga imposible la presentación de alternativas y su defensa.

Tal vez la conexión con el derecho de enmienda de los demás parlamentarios no fuera el motivo más acertado para declarar la inconstitucionalidad. En efecto, las enmiendas, cualesquiera que sean — homogéneas o heterogéneas — se debaten y votan, en comisión y en Pleno. Tampoco la incorporación de una enmienda homogénea y congruente que plantee una cuestión imprevista e imprevisible — y por tanto nueva - permite que aquella sea enmendada, salvo por vía de transacción en los términos reglamentarios. El argumento para la inconstitucionalidad debiera haber estribado en la vulneración del principio de seguridad jurídica que produce la inclusión de elementos heterogéneos en una ley, lo que no ha considerado contrario a la Constitución el Tribunal en la sentencia 136/2011.

Esta sentencia — dictada en el recurso contra la Ley 50/1998, de medidas fiscales, administrativas y del orden social y a la que nos referiremos a continuación por versar sobre la constitucionalidad de las leyes de contenido heterogéneo-confirma la doctrina revisada sobre las enmiendas, declarando: «la materia y el objeto del procedimiento lo delimita el autor de la iniciativa» (FJ 6). «Toda enmienda parcial tiene que tener un carácter subsidiario o incidental respecto del texto a enmendar, de modo que una vez que una iniciativa ha sido aceptada por la Cámara como texto de deliberación, no cabe alterar su objeto mediante las enmiendas al articulado...No caben enmiendas al articulado ajenas a la materia de la iniciativa, esto es, que no guarden una conexión de homogeneidad mínima con la misma. Cuando el ejercicio del derecho de enmienda al articulado no respete dicha conexión mínima de homogeneidad con el texto enmendado se estará afectando, de modo contrario a la Constitución, al derecho del autor de la iniciativa» (FJ 8).

En las sentencias136/2011 y 176/2011, aunque se alega la violación del derecho de enmienda, el Tribunal manifiesta que, más allá de un motivo genérico, los recurrentes no habían impugnado precepto alguno de la Ley controvertida que eventualmente pudiera haber adolecido de falta de homogeneidad en la introducción de enmiendas, no siendo función del Tribunal Constitucional investigar el contenido de la Ley impugnada a la búsqueda de los concretos preceptos respecto de los cuales se hubiese podido producir la situación denunciada en la demanda $(\mathrm{FJ} 8)^{24}$.

24 Frente a esta posición, que acoge la argumentación del Abogado del Estado, el magistrado Aragón, en su voto particular, considera que «sí estamos obligados a indagar qué enmiendas encubren verdaderos supuestos de iniciativa legislativa dada la publicidad oficial en el "Diario de Sesiones", y habida cuenta de que no somos árbitros, sino defensores de la supremacía de la Constitución y controladores de la constitucionalidad de las leyes (art. 27.1 LOTC), cuando, como sucede en el presente caso, sobre ello hemos sido requeridos por quienes se encuentran legitimados para promover un recurso de inconstitucionalidad (art. 162.1 CE y art. 32 LOTC), y que han argumentado suficientemente en su recurso sobre la existencia de este vicio de inconstitucionalidad que denuncian». Como recuerda F. SANTAOLALLA ( ¿ ¿Es la homogeneidad material condición indispensable de las iniciativas legislativas?», Revista de las Cortes Generales, n 83, 2011, pág. 159), en el antecedente 1.b de la sentencia se alude a los números de las enmiendas, tanto del Congreso como del Senado, respecto a las cuales se alegó la indebida utilización del derecho de enmienda, por lo que no habría resultado 
La sentencia 176/2011, referida a la Ley 55/1999, de medidas fiscales, administrativas y del orden social, al resumir la doctrina contenida en la 136/2011, recuerda que en el ejercicio del derecho de enmienda al articulado debe respetarse una conexión mínima de homogeneidad con el texto enmendado, «so pena de afectar, de modo contrario a la Constitución, tanto al derecho del autor de la iniciativa (art. $87 \mathrm{CE}$ ), como al carácter instrumental del procedimiento legislativo (art. 66.2 CE) y, en consecuencia, a la función y fines asignados al ejercicio de la potestad legislativa por las Cámaras, provocando un vicio en el desarrollo del citado procedimiento que podría alcanzar relevancia constitucional, si alterase de forma sustancial el proceso de formación de voluntad en el seno de las Cámaras» (FJ 2.d).

La sentencia 209/2012 (FJ 4), sobre la Ley 24/2001, de medidas fiscales, administrativas y del orden social, parte de lo ya expuesto en la sentencia 136/2011: si bien los principios y valores que subyacen en el correcto ejercicio del derecho de enmienda dentro del procedimiento legislativo - la conexión mínima de homogeneidad con el texto enmendado - han de ser respetados también en la tramitación de leyes de contenido heterogéneo, en éstas «la conexión de homogeneidad ha de entenderse de modo flexible que atienda también a su funcionalidad; y es que la pluralidad de materias sobre las que versa en tales casos la iniciativa legislativa no las convierte en leyes de contenido indeterminado, ya que éste queda delimitado en el concreto texto presentado para su tramitación parlamentaria (STC 136/2011, de 13 de septiembre, FJ 8)». El Tribunal examina la creación de tres tributos por la aprobación de sendas enmiendas, entendiendo que «la introducción de las tres enmiendas citadas en el texto de una iniciativa que precisamente hacía referencia a medidas tributarias en diferentes materias (impuestos y tasas) no sólo no está huérfana de la necesaria conexión material con el objeto de la iniciativa (STC 136/2011, de 13 de septiembre, FJ 8), sino que es congruente con su objeto, espíritu y fines esenciales (ATC 118/1999, de 10 de mayo, FJ 4), tanto más cuando la conexión reclamada no tiene que ser de identidad con las medidas previstas en el texto de la iniciativa, sino de afinidad con las materias recogidas en el mismo».

También en la sentencia 234/2012, de gran importancia por seguir la senda de la sentencia 46/1990 y anudar la seguridad jurídica a la técnica normativa en supuestos de remisiones defectuosas, se examina una enmienda para comprobar que guarda una conexión mínima de homogeneidad con la iniciativa legislativa, recogiendo la doctrina expuesta en las sentencias $119 / 2011$ y $136 / 2011^{25}$.

muy arduo localizar los preceptos resultantes; podría haber merecido mayor atención esta alegación, como denuncia el voto particular del magistrado Aragón Reyes.

25 Aunque no guarda relación con la homogeneidad de las enmiendas, citaremos aquí para completar la reciente doctrina sobre enmiendas la sentencia 238/2012, en el recurso de inconstitucionalidad contra la Ley Orgánica 2/2004, de modificación de la Ley Orgánica 6/1985, de 1 de julio, del Poder Judicial, en la que el Tribunal, al examinar los vicios de procedimiento alegados (FJ 5), admite la reducción del plazo de presentación de enmiendas - en el caso impugnado, a dos días - sobre la base de las facultades concedidas a la Mesa de la Cámara por el artículo 94 del Reglamento del Congreso, habiendo entendido la Mesa que se daba un caso excepcional que justificaba la reducción del plazo a menos de la mitad de lo que corresponde en supuestos urgentes. Existían circunstancias objetivas (se trataba de un proyecto de ley que reproducía otro anterior ya debatido que no alcanzó la mayoría requerida por error en la votación) y la reducción no impidió la presentación de enmiendas, que se discutieron y rechazaron, con lo que no existió vicio que afectara esencialmente al proceso de formación de la voluntad de los parlamentarios. 


\section{Enmiendas transaccionales}

En la sentencia 204/2011, en recurso de inconstitucionalidad sobre la Ley 21/2001, de 27 de diciembre, por la que se regulan las medidas fiscales y administrativas del nuevo sistema de financiación de las Comunidades Autónomas de régimen común y ciudades con Estatuto de Autonomía, el Tribunal toma como punto de partida (FJ 4) para examinar la alegada infracción del artículo 115 del Reglamento del Senado (RS) en la admisión de enmiendas transaccionales que materialmente no lo eran, el resumen de la doctrina contenida en la Sentencia 119/2011, FJ 6: deberá comprobarse que existe una correlación material entre la enmienda y el texto enmendado, teniendo en todo caso en cuenta que dicho juicio de conexión material o relación de homogeneidad debe realizarse con toda cautela, pues el procedimiento legislativo no puede verse atrapado en unas reglas tan rígidas que hagan del debate parlamentario un procedimiento completamente reglado. En este sentido, los órganos de gobierno de las Cámaras deben contar con un amplio margen de apreciación para determinar la existencia de conexión material entre enmienda y proyecto o proposición de ley objeto de debate (FJ 7 sentencia 119/2011).

El Tribunal examina a continuación las enmiendas transaccionales en cuestión, para concluir que no estaban en absoluto desconectadas del objeto del proyecto de ley y avalar la interpretación del artículo 115 RS en el sentido de que caben las enmiendas transaccionales que pretendan llegar a un acuerdo final entre el texto de la enmienda y el texto legislativo, y no sólo entre dos enmiendas, entendiendo también que el Presidente de la Comisión actuó dentro del necesario margen de apreciación para el que le faculta la norma al decidir su admisión. No se entiende acreditado que la eventual infracción del artículo 115 RS haya alterado de modo sustancial el proceso de formación de la voluntad parlamentaria ni restricción alguna a las facultades de las Cámaras.

Duque Villanueva ${ }^{26}$ considera que la solución dada en este caso a una infracción reglamentaria que le parece evidente, contrasta con la nueva doctrina constitucional elaborada en relación con la exigencia de conexión u homogeneidad entre la enmienda y el texto enmendado (sentencias 119/2011 y 136/2011) y las consecuencias de su ausencia, como vicio del procedimiento legislativo con transcendencia constitucional y lesión del ius in offcium de los parlamentarios ${ }^{27}$. Parte en la crítica de que se han utilizado las enmiendas transaccionales no para la finalidad prevista reglamentariamente — alcanzar un acuerdo entre las enmiendas y el texto legislativo- sino para introducir en el proyecto de ley remitido por el Congreso nuevos preceptos, «de suerte que en la práctica aquellas constituyeron nuevas enmiendas formuladas transcurrido ya el plazo de presentación de enmiendas».

A mi juicio, el problema está en la fundamentación sobre el derecho de enmienda de los parlamentarios adoptada por el Tribunal Constitucional para su decisión sobre las enmiendas incongruentes. No por añadirse nuevos artículos una enmienda deja de

26 J. DUQUE VILLANUEVA, «Doctrina del Tribunal Constitucional sobre el tercer cuatrimestre de 2011», REDC, n 94, 2012, pág. 306.

27 «La lógica de la doctrina y la solución adoptada en la STC 119/2011 parece que, proyectándola sobre las enmiendas transaccionales, habría de llevar en este caso a una solución diferente a la que alcanza en la sentencia». 
ser transaccional, sino por no responder a la finalidad de obtener un acuerdo, que puede versar sobre algún punto regulado en la ley o sobre alguno no regulado — siendo incluso necesaria la modificación de otra ley- pero congruente con ella; congruencia que, como aclara el Tribunal Constitucional en la sentencia 209/2012 FJ 4, significa no identidad de contenido, sino afinidad material. Además del respeto a las normas reglamentarias de procedimiento, es la congruencia la que marca la constitucionalidad de las enmiendas transaccionales: si son totalmente ajenas al objeto de la ley — faltas de esa conexión mínima que exige el Tribunal a las enmiendas ordinarias - aun presentadas en tiempo y forma, infringirán el principio de seguridad jurídica, sobre el que debería haber fundado el Tribunal su nueva doctrina, lo que le hubiera permitido ser a su vez consecuente al enjuiciar las enmiendas transaccionales y las leyes de contenido heterogéneo.

\section{Implementación de la doctrina constitucional: necesidad de una calificación previa de las enmiendas}

La doctrina contenida en la sentencia 119/2011 y posteriores va a requerir un cambio en la calificación de las enmiendas por los órganos de las Cámaras.

Como exponíamos hace ya unos años ${ }^{28}$, antes de la sentencia no existía en el Congreso en la práctica calificación alguna de las enmiendas al articulado: ni por la Mesa de la Cámara, pues éstas ni siquiera se registran con número en el Registro General, ni entran por tanto en el orden del día de la Mesa, sino que se trasladan directamente a la Comisión; ni por la Mesa de la Comisión, la cual se limita, de conformidad con la Resolución de 12 de enero de 1983, a calificar las enmiendas a la totalidad y las que supongan aumento de créditos o disminución de ingresos presupuestarios, y ello a pesar de que la Resolución de la Presidencia de 23 de septiembre de 1986 atribuye a la Mesa de la Comisión declarar la admisión a trámite de las enmiendas que afecten al articulado.

Más allá de las enmiendas a la totalidad encubiertas, no se desarrolla, pues, una calificación material que examine la homogeneidad y congruencia de las enmiendas con el texto enmendado. Ni siquiera existe un control formal: las enmiendas fuera de plazo siguen su eventual trámite de convalidación independiente; si todavía no han sido admitidas previa audiencia de la Junta de Portavoces, no serán examinadas por la ponencia, pero por exclusión por parte de la secretaría administrativa de la Comisión, no de su Mesa. También será la secretaría la que alerte de un defecto no subsanado en la legitimación, y los servicios jurídicos, en la medida de lo posible, quienes corrijan los defectos en la identificación del precepto o texto enmendado (cuando sea patente el error) o pidan aclaraciones a los autores.

Ya entonces abogábamos por que se realice una calificación de las enmiendas al articulado $^{29}$, que sabemos no puede abarcar la Mesa de la Cámara por su volumen, pero que puede descentralizarse en las Mesas de las Comisiones, que verían potenciada su labor, a la vez que mejoraría sustancialmente la corrección técnica de nuestras leyes.

28 P. GARCÍA-ESCUDERO MÁRQUEZ, El procedimiento legislativo ordinario en las Cortes Generales, cit., págs. 278-279.

29 En el mismo sentido, M. SENÉN, «El asesoramiento jurídico en el procedimiento legislativo», en $E l$ procedimiento legislativo. V Jornadas de Derecho Parlamentario, Congreso de los Diputados, Madrid, 1997, pág. 516. 
Tras la sentencia 119/2011, la única Cámara que se dio por aludida fue el Senado, cuya mesa también realiza un control de las enmiendas al Proyecto de Ley de presupuestos para ver si exceden de su contenido propio, según la jurisprudencia del Tribunal Constitucional. Véase BOCG Senado ${ }^{\circ} 131$, de 7 de diciembre de 2012, nº 68, de 11 de junio de 2012, no $77 \mathrm{~K}$, de 10 de diciembre de 2010, n 304, de 3 de diciembre de 2009, $\mathrm{n}^{\circ} 4 \mathrm{~h}$, de 2 de diciembre de 2008, Cámara contra la que se dirigía el recurso de amparo. A partir de ahí y hasta el final de la IX legislatura en septiembre del mismo año (es decir, apenas dos meses) encontramos cierto número de acuerdos de inadmisión de enmiendas por la Mesa de esta Cámara ${ }^{30}$.

Al iniciarse la X legislatura, y ya dictada la sentencia 136/2011, de 13 de septiembre, que no limitaba al Senado su doctrina sobre las enmiendas heterogéneas, debía haber habido una reacción por ambas Mesas. La del Senado dio un paso atrás ya al final de la legislatura anterior, en el sentido de admitir a trámite las enmiendas incongruentes cuando están avaladas por todos los grupos, de manera que las rechazadas son menos frecuentes $^{31}$. En el Congreso no ha existido acuerdo alguno al respecto, sin perjuicio de que la Mesa de alguna Comisión haya inadmitido una enmienda transaccional incongruente al amparo del artículo 114.3, según el cual: «Durante la discusión de un artículo, la Mesa podrá admitir a trámite nuevas enmiendas que se presenten en este momento por escrito por un miembro de la Comisión, siempre que tiendan a alcanzar un acuerdo por aproximación entre las enmiendas ya formuladas y el texto del artículo. (...)» ${ }^{32}$.

30 Véanse ejemplos en BOCG Senado $\mathrm{n}^{\circ} 104$, de 3 de agosto de 2011 (enmiendas a dos proyectos), $\mathrm{n}^{\circ}$ 108, de 8 de septiembre de 2011 y n $^{\circ} 111$, de 14 de septiembre de 2011. Las inadmisiones se hacen «al amparo del artículo 36.1 c) del Reglamento del Senado [facultades de calificación de la Mesa de la Cámara] y de conformidad con la jurisprudencia del Tribunal Constitucional establecida en su sentencia de 5 de julio de 2011», por considerar que las enmiendas «se refieren a materias que carecen de manera evidente y manifiesta de conexión» con el respectivo Proyecto de ley. Véase, no obstante, que la Mesa admite dos enmiendas «que aun considerando que las mismas se refieren a materias que carecen de manera evidente y manifiesta de conexión con dicho proyecto de ley, han sido firmadas por todos los grupos parlamentarios, lo que permite inferir que, en principio, su admisión a trámite no produce vulneración del derecho fundamental del artículo 23.2 de la Constitución». La admisión de las enmiendas «unánimes» se basa en la presunción de que no se vulneran derechos de los parlamentarios, sin perjuicio de la posibilidad de que algún senador recurra la admisión ante la Mesa.

31 Pueden verse, no obstante, en BOCG Senado n ${ }^{\circ} 119$, de 14 de noviembre de 2012, o n ${ }^{\circ} 136$, de 14 de diciembre de 2012. En este caso, la inadmisión se produce por considerar que lo que en ellas se plantea «carece de manera evidente y manifiesta de conexión con el objeto del Proyecto de ley que se tramita, tal y como se desprende de la descripción individualizada de cada una de ellas» que sigue a continuación. También hay motivación con explicitación del contenido de la enmienda inadmitida en el primer ejemplo citado. En términos similares, en BOCG $\mathrm{n}^{\circ} 117,12$ noviembre 2012; n ${ }^{\circ} 101,4$ octubre 2012, nº 70, 13 junio 2012; $\mathrm{n}^{\circ} 108,8$ septiembre 2011 .

32 En la Comisión de Justicia de 26 de noviembre de 2012, durante la tramitación del Proyecto de Ley Orgánica de medidas de eficiencia presupuestaria para la Administración de Justicia, se inadmitió una enmienda in voce del Grupo Socialista que pretendía incluir la derogación de la Ley 10/2012, por la que se regulan determinadas tasas en el ámbito de la Administración de Justicia y del Instituto Nacional de Toxicología y Ciencias Forenses (Diario de sesiones de la Comisión, no 215, págs. 13 y 15), confirmando la Mesa de la Cámara la inadmisión el 29 de noviembre de 2012. Sobre la incongruencia de enmiendas, protestando contra la inadmisión, véase la intervención del diputado socialista Sr. Muñoz en el Pleno del Congreso, Diario de Sesiones $\mathrm{n}^{\circ} 78$, de 29 de noviembre de 2012, pág. 11. Una enmienda similar, presentada por el Grupo Catalán CIU sería inadmitida en el Senado (BOCG Senado nº 136, de 14 de diciembre de 2012). 
La situación, como puede verse, lejos de estar resuelta con carácter general, recuerda a la estrategia de meter la cabeza debajo del ala y esperar los eventuales recursos. Frente a esto, cabría reclamar una reforma de los Reglamentos (art. 110 RC Congreso y 107.2 RS) en el sentido de exigir la congruencia de las enmiendas con el objeto material de la iniciativa legislativa (por tomar la redacción del Reglamento del Parlamento de Cataluña) o que «tengan una relación material mínima» con aquella, como propone Santaolalla ${ }^{33}$. No en vano, la sentencia 119/2011 declara que son «los Reglamentos parlamentarios [quienes] de acuerdo con la Constitución deben articular los procedimientos, pero siempre respetando el ius in officium en todas sus fases» (FJ 8).

La incorporación del requisito supondría asimismo determinar el órgano al que ha de encomendarse el control de su cumplimiento. Ya hace tiempo propusimos que fueran las Mesas de las Comisiones las competentes, con posibilidad de recurso ante la Mesa de la Cámara, para obtener una mayor agilidad en el trámite legislativo, que suele apresurarse una vez concluido el plazo de enmiendas en el Congreso, y que nunca está sobrado de tiempo en el Senado ${ }^{34}$. A ello se unen razones de eficiencia y división del trabajo, de acuerdo con el principio de especialidad de las comisiones legislativas permanentes, a las que asisten los Letrados de las Cortes Generales.

Para atribuir la competencia a la Mesa de las Comisiones, en el caso del Congreso bastaría con modificar la Resolución de la Presidencia sobre normas que regulan la calificación de los escritos de enmiendas presentadas a textos legislativos, de 12 de enero de 1983, que sólo les faculta para calificar las enmiendas a la totalidad y las que supongan aumento de crédito o disminución de los ingresos presupuestarios, con posterior reclamación ante la Mesa de la Cámara contra el acuerdo de calificación. O bien cuando esta competencia se reitera, en lo que a la calificación de enmiendas a la totalidad y declaración de admisión a trámite de las que afecten al articulado, en la Resolución de desarrollo del artículo 113 del Reglamento sobre designación y funciones de las ponencias, de 23 de septiembre de 1986.

Recordemos que de acuerdo con las matizaciones formuladas en la sentencia 119/2011, lo que debe constatar la Mesa, con un amplio margen de apreciación, es la falta absoluta de conexión, siendo motivada la valoración sobre la existencia o no de dicha conexión mínima, conexión de homogeneidad que, como señala la sentencia 209/2012, debe entenderse de modo flexible que atienda también a su funcionalidad, sobre todo en las leyes de contenido heterogéneo.

33 F. SANTAOLALLA, «¿Es la homogeneidad material condición indispensable de las iniciativas legislativas?», cit., pág. 161.

34 P. GARCÍA-ESCUDERO MÁRQUEZ, El procedimiento legislativo ordinario en las Cortes Generales, cit., pág. 279. F. SANTAOLALLA, «¿Es la homogeneidad material condición indispensable de las iniciativas legislativas?», cit., pág. 161 propone que sea incluso el Presidente de la Comisión por delegación. Creemos que, en todo caso, la práctica iría imponiendo su actuación. Este autor considera que, tras el recurso ante la Mesa o el Presidente de la Cámara (en el Congreso, foro de tantas confrontaciones políticas, es más realista pensar en la actuación de órganos colegiados de composición plural) no debería existir una prolongación en el recurso de amparo, aunque no es descartable. Efectivamente, no es descartable, sino incluso probable, su presentación. Otra cosa es que el Tribunal les aplique estrictamente el requerimiento de la especial trascendencia constitucional, que Santaolalla opina vendría a confirmar la inutilidad de la citada vía. 


\section{LEYES DE CONTENIDO HETEROGÉNEO}

Si con la sentencia 119/2011 hemos avanzado hacia la homogeneidad de las leyes y la claridad del ordenamiento, lamentablemente en la sentencia 136/2011 el Tribunal no ha mantenido un criterio riguroso y clarificador respecto de las leyes de contenido heterogéneo — singularmente, las llamadas leyes de medidas o de acompañamiento a la Ley de Presupuestos, una de las cuales constituía el objeto del recurso-, pues no ha considerado que lesionen la seguridad jurídica. Coincido plenamente con el voto particular del magistrado Aragón Reyes en que el recurso ofrecía al Tribunal la ocasión de poner coto a la práctica de estas leyes, y creo que la puerta se ha cerrado en falso, cuando cabía haber hecho alguna distinción entre contenido heterogéneo de las leyes y preceptos intrusos, que es lo que voy a intentar realizar, tras exponer el contenido de la sentencia.

\section{Cuestión previa: las leyes deben ser completas y homogéneas}

a) La ley debe ser completa

Las normas de técnica legislativa prescriben que la ley debe contener la regulación completa de su objeto material, evitando en la medida de lo posible la dispersión normativa, esto es, la regulación parcial de una misma materia en varias leyes distintas, pues esto complica el ordenamiento y dificulta el conocimiento y localización de la normativa aplicable.

La confusión no deriva sólo del número de leyes, sino también de que estas son fragmentarias, sectoriales, estratificadas, provocando lo que V. Italia califica de dodecafonía jurídica, que sitúa al intérprete ante un mosaico impreciso frente a la solemne arquitectura de los códigos ${ }^{35}$. Como señala la Directriz n. ${ }^{\circ} 3$ de Técnica Normativa, en la medida de lo posible, en una misma disposición deberá regularse un único objeto, todo el contenido del objeto y, si procede, los aspectos que guarden directa relación con él.

Podemos coincidir con el Tribunal Constitucional cuando considera que la normación completa de una materia en una ley o por partes en varias leyes forma parte del ámbito de decisión del legislador, «salvo en aquellos casos en que la Constitución establece la unidad de legislación en una misma materia o para un conjunto de problemas o soluciones enlazados y próximos entre sí, sin perjuicio de que una vez establecida esta legislación pueda modificarse parcialmente», como ocurre en el caso de la ley electoral (STC 72/1984, FJ 5) ${ }^{36}$. En la sentencia 5/1982 (FJ 1) el Tribunal señala que «la interdicción de una nor-

35 V. Italia, La fabbrica delle leggi. Leggispeciali e leggi di principi, 2. a ed., Giuffrè, Milán, 1994.

36 «En todos los casos en que el legislador es soberano y le corresponde la decisión de legislar o de no legislar nada le impide que la normación de una determinada materia se lleve a cabo por partes. Lo mismo puede decirse en aquellos casos que el legislar sea una obligación impuesta por la Constitución. Si la Constitución no establece lo contrario - y lo contrario ha de entenderse siempre excepcional—, corresponde a la oportunidad política decidir si la legislación se hace por partes o de una sola vez. Sin embargo, no puede aplicarse el mismo criterio a aquellos otros casos en que por las razones que fueran la Constitución establezca la unidad de legislación para una sola materia o para un conjunto de problemas y situaciones enlazadas y próximas entre sí, sin perjuicio de que una vez establecida esta legislación pueda modificarse parcialmente». 
mación parcial de una determinada materia implicaría, sin duda, una norma excepcional que sólo puede estimarse existente cuando explícitamente ha sido establecida».

No obstante, como señala Sáinz Moreno, la regulación fragmentada de una materia en distintas normas sólo está justificada cuando lo exige la distribución de las competencias normativas (entre Unión Europea y Estados miembros, entre el Estado y las Comunidades Autónomas), el principio de reserva de ley o la Constitución cuando obliga a incluir ciertas regulaciones en normas asignadas nominativamente (por ejemplo, artículos 70, 104, 107 y $122 \mathrm{CE}$ ). En el resto de los casos, debería procurarse optar por la unidad, en aras de la claridad del ordenamiento y de la consiguiente seguridad jurídica.

\section{b) La ley debe ser homogénea}

Hemos reseñado ya normas de Derecho comparado, incluso constitucionales, que exigen la homogeneidad en las iniciativas ${ }^{37}$. Así, las Constituciones de Colombia y Grecia. A ellos se añade el artículo 148 de la Constitución de Ecuador, que establece: «Los proyectos de ley deberán referirse a una sola materia y serán presentados al Presidente del Congreso con la correspondiente exposición de motivos. Si el proyecto no reuniere estos requisitos no será tramitado» ${ }^{38}$

Por apuntar algún ejemplo más de nuestro entorno, citaremos el Handbuch der Rechtsförmlichkeit ${ }^{39} \mathrm{o}$ Manual de Técnica jurídica alemán, que aunque admite las leyes de contenido variado o «leyes de artículos» como una de las posibilidades para configurar las modificaciones legislativas, exige que las modificaciones guarden «relación mutua por su contenido» y los diversos cambios sustantivos «una conexión objetiva entre ellos».

La no limitación material del contenido de las iniciativas y las enmiendas ha dado lugar en nuestro país a la proliferación de leyes de modificación múltiple, técnicamente

$37 \mathrm{Al}$ principio de este trabajo citamos el art. 101.2 del Reglamento del Parlamento de Cataluña de 2005 y el art. 5.2 c) de la Ley Orgánica 2/1984, de 26 de marzo, reguladora de la iniciativa legislativa popular.

38 Para el estado de la cuestión en Estados Unidos, véase I. M. GIMÉNEZ SÁNCHEZ, «Las leyes de acompañamiento y el problema de las "leyes ómnibus"», Teoría y realidad constitucional, n 22, 2008, págs. 534 y ss. La cláusula que exige que las leyes sólo puedan tratar de una única materia, que debe venir recogida expresamente en el título de la misma, existe ya en varias de las Constituciones de los Estados, como Tennessee y Ohio, y se defiende su inclusión en la Constitución de los Estados Unidos.

39 Parte D. Leyes modificativas, 4. La ley de contenido variado (Das Mantelgesetz). Puede verse en español en Técnica normativa de la Unión Europea, ed. F. Santaolalla López, vol. I, Senado, Madrid, 2008, pág. 295. En Francia, la Circular de 30 de enero de 1997, relativa a las reglas de elaboración, firma y publicación de los textos en Diario Oficial y a la aplicación de procedimientos particulares que incumben al Primer Ministro (2. Elaboración de los textos. 2.3 Reglas particulares a las leyes «que incluyen distintas disposiciones relativas a...» [sic]), expone: «La práctica de los proyectos de ley que incluyen distintas disposiciones de carácter financiero o social se ha extendido a otros sectores (función pública y educación nacional, en particular). Estos proyectos agregan disposiciones dispares, destinadas principalmente a insertarse en distintos textos anteriores, que ellas ajustan, enmiendan o completan. Estos textos constituyen, sin duda, un mal necesario, pues permiten evitar la multiplicación de leyes autónomas de alcance muy limitado o de enmiendas gubernamentales a textos en debate. Sus inconvenientes deben, sin embargo destacarse. (...) Estos proyectos de ley tienen un aspecto compuesto y puntillista que priva a la ley de sus notas de solemnidad, generalidad y permanencia. Su utilización debe, por tanto, reducirse y, en cualquier caso, nunca implicar importantes reformas de fondo. $\mathrm{Si}$ varias disposiciones pueden formar un todo coherente, conviene hacer con ellas uno o más proyectos de ley autónomos, con títulos precisos. La ley ganará con ello en claridad y el procedimiento de elaboración en rapidez» (Ibidem, vol. II, págs.. 996-997). 
defectuosas, como las llamadas leyes ómnibus, y de los preceptos intrusos, con efectos dañinos para la claridad del ordenamiento y la seguridad jurídica. En ambos casos, —normas intrusas y leyes modificativas, cuando son múltiples_ el título no refleja, ni puede reflejar, su contenido ${ }^{40}$, de manera que resulta imposible prever y difícil detectar por el título que la ley incluye una norma reguladora de una materia determinada ${ }^{41}$.

Nos hemos preguntado: ¿es acaso previsible que una Ley reguladora del régimen de las tasas y precios públicos modifique la Ley del Impuesto de sucesiones y donaciones o la Ley del Impuesto de transmisiones patrimoniales y actos jurídicos documentados? ${ }^{42}$

A veces se critica la prolijidad de determinados títulos de las leyes ${ }^{43}$, pero en el título, como elemento identificador y de información, parece casi preferible pecar por exceso que por defecto, si ello contribuye a preservar la seguridad jurídica. Otras veces, el problema no reside en la mayor o menor extensión, sino en la imprecisión terminológica o en que el título no sea representativo de su contenido.

Muchos son los supuestos de falta de homogeneidad, originaria de la iniciativa o derivada de la introducción de enmiendas, que podríamos citar. Ejemplos de introducción de confusión que puede llegar a vulnerar la seguridad jurídica serían las modificaciones «encubiertas» de leyes, de las que no da cuenta el título de la ley, como es el caso de aquellas leyes orgánicas cuya tramitación se aprovecha para introducir, al final de un periodo de sesiones o de una legislatura, cualesquiera cuestiones, relacionadas o

40 En palabras de P. SALVADOR CODERCH («El título de las leyes», en Curso de Técnica legislativa Gretel, CEC, Madrid, 1989, pág. 65), no hay buen título para un mal contenido.

41 Recordemos, como lo hace, por ejemplo, el Dictamen 294/2004 del Consejo Consultivo de Andalucía (citado por J. L. MARTÍN MORENO, «Título de las leyes y homogeneidad», Revista española de la función consultiva $\mathrm{n}^{\circ}$ 6, 2006, págs. 173-174) que las leyes no están destinadas exclusivamente a los juristas ni a los especialistas. «Los ciudadanos son normalmente los destinatarios de las normas, normas que en no pocas ocasiones les afectan directamente, algo que se puede comprender fácilmente en presencia de normas tributarias. Por todo ello, el título de la ley, identificando con precisión su contenido, debe resultar fácilmente reconocible por los ciudadanos (y por los no expertos), y no sólo eso, sino que, además, debe facilitar su conocimiento y cita».

42 Véanse las disposiciones adicionales sexta y séptima (sin rúbrica, a diferencia de las restantes disposiciones adicionales, como evidencia de su inclusión apresurada en la tramitación parlamentaria) de la Ley 25/1998, de 13 julio, de modificación del Régimen Legal de las Tasas Estatales y Locales de Reordenación de las Prestaciones Patrimoniales de Carácter Público. En una ley anterior, la Ley 8/1989, de 13 de abril, de Tasas y Precios Públicos, la disposición adicional cuarta, procedente de una enmienda introducida en el Senado, regulaba el «tratamiento fiscal de las diferencias de valor resultantes de la comprobación administrativa» en las transmisiones onerosas. Impugnado el precepto, la STC 194/2000 declaró su inconstitucionalidad por razones de fondo, rechazando previamente las alegaciones procedimentales, entre las que se encontraba el que por vía de enmienda se hubiera introducido un precepto absolutamente ajeno a la materia regulada en el proyecto (véase supra, nota 16).

43 Plagados de excrecencias, según J. L. MARTÍN MORENO («Título de las leyes y homogeneidad», cit., pág. 171 y ss.), «sumidos en un propósito estéril de abarcar los contenidos principales, accesorios y hasta meramente accidentales de una norma, sin que nada falte», «títulos que crecen en proporción a la voracidad de contenidos de las leyes». La precisión — continúa este autor- no es, ni mucho menos, directamente proporcional a la extensión del título; basta con hallar el hilo conductor, el eje vertebrador de una determinada disposición, porque lo demás, aunque aporte información, puede ser considerado innecesario e incluso perturbador, en la medida en que venga a destacar algunos aspectos de la regulación frente a otros que pueden tener igual o mayor relevancia a la hora de integrarlos en el título de la disposición. 
no, que en el entretanto se han convertido en objetivos políticos prioritarios o urgentes y requieren su regulación mediante ley orgánica ${ }^{44}$.

Debe alertarse sobre el problema de las modificaciones «escondidas» o de difícil localización, que versan sobre materias distintas a la regulada en la ley y sin que quede constancia en el título de la modificación, pues perjudican gravemente a la seguridad jurídica ${ }^{45}$.

Merecen una mención en el cuadro de honor del disparate legislativo la Ley 37/2010, de 15 de noviembre, por la que se crea la Oficina presupuestaria de las Cortes Generales, cuya disposición final primera modifica el Código de la circulación en materia sancionadora, la Ley 43/2010, de 30 de diciembre, del Servicio postal universal, de los derechos de los usuarios y del mercado postal (cuyas anomalías requieren una nota específica ${ }^{46}$ ), y la Ley 40/2010, de 29 de diciembre, de almacenamiento geológico de dióxido de carbono, cuyas disposiciones finales séptima a décima introducen modificaciones en las leyes reguladoras de los impuestos sobre sucesiones y donaciones, sobre la renta y sobre sociedades, así como sobre la Ley del Catastro inmobiliario, de las que — a causa de su tardía y precipitada inclusión en el Senado - no se da noticia, no ya en el título de la ley, sino tampoco en el preámbulo o en la mención de los títulos competenciales en virtud de los que aquella se $\operatorname{dicta}^{47}$.

44 Un ejemplo típico sería una LO de modificación de la LOPJ. En el ámbito de la ley ordinaria ocurría lo mismo con las «leyes de medidas», que se convertían en leyes-escoba para incluir toda aquella regulación que debía entrar en vigor al inicio del siguiente ejercicio. Otro ejemplo sangrante de ley de contenido heterogéneo, aunque halle reflejo en el título, es la Ley Orgánica 8/2010, de 4 de noviembre, de reforma de la Ley Orgánica del Régimen Electoral General (para modificar el régimen de suplentes y la papeleta para las elecciones al Senado) y de la Ley Orgánica del Tribunal Constitucional (para regular los efectos del retraso en la elección de sus miembros), en la que la reforma de esta segunda ley se introduce por una enmienda durante la tramitación en el Congreso de los Diputados, que convierte a la norma en bicéfala por englobar dos materias absolutamente diversas, provocando además numerosos defectos técnicos en la misma: preámbulo asimétrico, con tres líneas dedicadas a la segunda reforma, orden no cronológico de las normas legales que se modifican; de los dos artículos, el primero no lleva rúbrica y el segundo sí; entrada en vigor el mismo día de la publicación...

45 Puede verse una enumeración de ejemplos que resultan hasta divertidos, si no fuera por los efectos que producen sobre la seguridad jurídica en L. ZARRALUQUI SÁNCHEZ-EZNARRIAGA, «El bosque legislativo», Otrosí, págs. 25 y ss., y «El ordenamiento jurídico bajo camuflaje», Revista del Consejo General de la Abogacía Española, $n^{\circ}$ 49, 2008. Concluye: «En consecuencia, cuando en el marasmo legislativo se esconden las normas tras árboles frondosos en selvas impenetrables, no puede presumirse su conocimiento ni puede exigirse su cumplimiento, constituyendo, en todo caso, una flagrante violación de la seguridad jurídica, impropia de un Estado de Derecho». Véase también A. V. SEMPERE NAVARRO, «El escondite jurídico», Actualidad Jurídica Aranzadi, $\mathrm{n}^{\circ}$ 746, 2008.

46 Las disposiciones adicionales (por cierto, conforme a la directriz 42, las normas que modifiquen el derecho vigente, cuando la modificación no sea objeto principal de la disposición, han de incluirse en las disposiciones finales, añadiendo que tales modificaciones tendrán carácter excepcional) octava a décima contienen normas sobre cuentas de compensación de sociedades concesionarias de autopistas de peaje (la disposición adicional octava adopta la estructura de una ley independiente, con su objeto, su ámbito de aplicación, su régimen normativo y su propia entrada en vigor), plazo para delegación legislativa en materia de puertos de interés general y autorización de rellenos en el dominio público del puerto de Bilbao, materias todas ellas de evidente falta de conexión con la que constituye el objeto de la Ley.

47 Aunque cabría pensar que la temática es más próxima, la disposición final cuarta de la Ley 5/2012, de 6 de julio, procedente del Real Decreto-ley 5/2012, de 5 de marzo, de mediación en asuntos civiles y mercantiles, modifica el acceso de los Licenciados en Derecho a la profesión de abogado regulado por la 
En los casos reseñados, la causa de la aberración es que la ley «pasaba por aquí» en un momento en que se consideraba urgente la regulación por ley de una cuestión en materia totalmente ajena a la misma, y el efecto es la incoherencia —y consiguiente complicación- en el ordenamiento jurídico, con evidentes efectos negativos sobre la seguridad jurídica. Aboguemos, pues, por una mayor racionalidad en el legislador que garantice la homogeneidad en el contenido de las leyes aprobadas y, a ser posible, la regulación por entero de una materia en una sola ley.

c) Las leyes de modificación múltiple y ómnibus

Especial atención, por su incidencia y eventual peligrosidad para el ordenamiento, merecen las leyes modificativas, esto es, aquellas que tienen por objeto la reforma de una o varias leyes, cuyo caso extremo constituyen las llamadas leyes ómnibus. Pese a que todas las reglas de técnica legislativa las anatematizan, estas leyes existen, se multiplican y dificultan el conocimiento del derecho vigente hasta límites insospechados.

De acuerdo con dichas reglas ${ }^{48}$, en la medida de lo posible las leyes modificativas tendrán por objeto la modificación de una sola ley, lo que se indicará en el título. Deben evitarse las leyes de modificación múltiple (que modifican varias leyes), porque dificultan el conocimiento y la localización de las modificaciones legislativas, lesionando la seguridad jurídica. Es preferible la aprobación de una nueva ley que sustituya a la anterior a la aprobación de una ley modificativa: como regla general, es preferible que exista una única disposición a la coexistencia de la norma originaria y sus posteriores modificaciones. Por tanto, las disposiciones modificativas deberán utilizarse con carácter restrictivo.

Las leyes modificativas presentan particularidades en cuanto a su forma y estructura, que deben ser observadas para una mayor certeza en los efectos que producen en el ordenamiento, y que afectan a su título, división y estilo, en el que debe distinguirse adecuadamente el texto marco — que pertenece a la ley de reforma o modificativa- del texto de regulación, que se insertará en la ley modificada.

En la medida de la posible, la ley modificativa no debe contener disposiciones materiales (sí la entrada en vigor, por ejemplo) distintas de la modificación, porque la ley que no tiene otro objeto que la modificación carece de otro alcance jurídico y, por tanto, agota sus efectos con su entrada en vigor, subsistiendo sólo la ley modificada en su nueva redacción, que continúa regulando el conjunto de la materia. Las modificaciones

Ley 34/2006. Este precepto figuraba ya en el Decreto-Ley, con constancia en su Exposición de Motivos. Por su parte, la Ley 10/2012, por la que se regulan las tasas en el ámbito de la Administración de Justicia y del Instituto Nacional de Toxicología y Ciencias Forenses, regula la supresión de la paga extraordinaria de los miembros del poder judicial y del Ministerio Fiscal, precepto en este caso introducido por enmienda. En ambos supuestos, podría darse una conexión material mínima, la competencia del Ministerio de Justicia, pero son preceptos ajenos al objeto y finalidad del proyecto de ley.

48 Véanse las Directrices de Técnica Normativa, $\mathrm{n}^{\circ} 50$ ( "Carácter restrictivo. Como norma general, es preferible la aprobación de una nueva disposición a la coexistencia de la norma originaria y sus posteriores modificaciones. Por tanto, las disposiciones modificativas deberán utilizarse con carácter restrictivo») y $\mathrm{n}^{\circ}$ 52: «Restricción de las modificaciones múltiples. Deben evitarse las modificaciones múltiples porque alteran el principio de división material del ordenamiento y perjudican el conocimiento y localización de las disposiciones modificadas». 
posteriores deberán hacerse en relación con la ley originaria, aunque su cita se complete con las modificaciones que ha experimentado.No debe olvidarse tampoco que las modificaciones se integran en el texto de la ley preexistente, por lo que debe respetarse su estructura y terminología.

Las leyes ómnibus, esto es, aquellas cuyo objeto lo constituye la modificación de cierto número de leyes (frecuentemente elevado) unidas o no por razones de política coyuntural o por la materia, son las más denostadas por su carácter perjudicial para el ordenamiento, dada la confusión que en él introducen. Su ejemplo más característico lo constituyen las leyes de medidas fiscales, administrativas y del orden social, que año tras año durante una década han ido modificando varias decenas de leyes del ordenamiento estatal y que perviven en el ámbito autonómico ${ }^{49}$, así como más o menos disfrazadas en aquel.

Como señala García de Enterría ${ }^{50}$, bastantes de las objeciones que el Tribunal Constitucional puso a la práctica anterior de legislar a través de la Ley de Presupuestos resultan aplicables a la técnica alternativa de las leyes de acompañamiento ${ }^{51}$, lo que, a nuestro juicio, puede generalizarse a otras leyes ómnibus. Tómese cualquiera de estas leyes: podemos seguir citando al maestro García de Enterría para afirmar que «cualquier intento de sistematizar este inmenso material normativo resulta de una increíble complejidad; más aún, cabe llanamente decir: imposible... Se dispersa, pues, sin razón apreciable para el lector ordinario, una misma regulación o una misma ley, que resulta pulverizada en lugares diversos cuya localización es una especie de juego cabalístico, porque, al menos para el lector ingenuo que yo soy, no parece fácil adivinar el criterio seguido» ${ }^{52}$.

49 «Esta práctica perturbadora, dice F. RUBIO LLORENTE, que se reproduce miméticamente en las Comunidades Autónomas, no es privativa de este país..., lo que hace más aconsejable aún una profunda reflexión sobre sus causas y sus indeseables efectos... Estas leyes ómnibus, que no respetan ningún límite ni obedecen a un criterio inspirador homogéneo, no son sino una respuesta compulsiva y cómoda, no exenta de oportunismo, a las demandas reguladoras, supuestamente apremiantes, de las instituciones públicas o los grupos sociales» («El papel del Consejo de Estado en el control de la calidad técnica de las normas», cit., pág. 36).

50 E. GARCÍA DE ENTERRÍA, Justicia y seguridad jurídica en un mundo de leyes desbocadas, Civitas, Madrid, 1999, págs. 80-81. «Resulta completamente insoportable esta técnica de legislar en bloque, asistemáticamente, sin motivación alguna visible (recordemos que las normas comunitarias deben estar motivadas circunstanciadamente, art. 190 del Tratado CE), simple fruto aparente del arbitrio y no de la razón legislativa, que parece que es la que debiera manifestarse en el debate de las Cámaras según la teoría democrática, de hecho fruto de iniciativas ocasionales y arbitristas de los distintos servicios administrativos, y cuyo texto final resulta normalmente inextricable para el lector incluso más despierto, que necesitará un esfuerzo excepcional para llegar a hacerse cargo del efecto innovativo global que tan expeditivamente se ha introducido en el ordenamiento».

51 «Y por de pronto la objeción clásica relativa a las limitaciones con que se tramitan, excluyendo la intervención de las comisiones de las Cámaras competentes por razón de la materia» (ibidem).

52 Ibidem, págs. 81-83. Enterría toma como ejemplo la Ley de Medidas para 1999 (objeto precisamente de la STC 136/2011) para demostrar que, aparte de modificar sesenta y seis leyes, algunas eran recién aprobadas y que incluso no habían aún entrado en vigor. «Se comprende que con todo esto la inseguridad jurídica aparece en estado casi puro, rectificando la ingenua creencia de Benjamín Constant en la regla de la predictibilidad absoluta de normas y conductas que aportarían necesariamente las leyes» (pág. 86). Tras criticar las cuarenta y cuatro disposiciones adicionales y seis finales, asimismo modificativas de leyes anteriores, afirma: «Todo este extraño y anómalo proceder del Legislativo no está hecho precisamente para facilitar el conocimiento - y, por tanto, la fluida aplicación— de las leyes y más bien hace de la posibilidad de ese conocimiento casi una hazaña esforzada, que sólo algunos expertos...son capaces de llevar a término, si alguno». 
Se argüirá que las leyes de medidas han desaparecido, al menos en el ordenamiento estatal. Pero donde se cierra una puerta, se abren ventanas para obtener los mismos efectos: el retorno de las modificaciones de leyes a la Ley de Presupuestos Generales del Estado, véanse las diecisiete y veinticuatro disposiciones finales, respectivamente, de las Leyes 2/2008 y 39/2010, de Presupuestos Generales del Estado para el año 2009 y el año $2011^{53}$. O rendijas, como la Ley que acompañó a la primera, Ley 4/2008, de 23 de diciembre, por la que se suprime el gravamen del Impuesto sobre el Patrimonio, se generaliza el sistema de devolución mensual en el Impuesto sobre el Valor Añadido, y se introducen otras modificaciones en la normativa tributaria, que sólo modifica diez leyes tributarias en su articulado, además de otras tres en las disposiciones finales ${ }^{54}$. En otros ámbitos, las leyes ómnibus siguen gozando de buena salud: véase, por ejemplo, la Ley 13/2009, de 3 de noviembre,de reforma de la legislación procesal para la implantación de la nueva oficina judicial (que modifica en torno a mil artículos de diecinueve leyes, entre ellos unos trescientos ochenta de la Ley de Enjuiciamiento Civil de 2000), o la Ley 25/2009, de modificación de diversas leyes para su adaptación a la Ley sobre el libre acceso a las actividades de servicios y su ejercicio, que modifica cuarenta y ocho leyes. O la Ley 2/2011, de 4 de marzo, de Economía sostenible, que — pese a recoger en sus artículos 4 a 7 los principios e instrumentos para la mejora de la regulación, entre los que se incluye la simplicidad en un marco normativo sencillo, claro y poco disperso, y el principio de seguridad jurídica, para cuya garantía «las facultades de iniciativa normativa se ejercerán de manera coherente con el resto del ordenamiento para generar un marco normativo estable y predecible, creando un entorno de certidumbre...»- a lo largo de su articulado, de sus 17 disposiciones adicionales y de sus 60 disposiciones finales modifica un centenar de leyes ${ }^{55}$.

Distintos autores ${ }^{56}$ y organismos ${ }^{57}$ han criticado las leyes de medidas fiscales, o en general las leyes ómnibus por sus efectos perniciosos sobre el ordenamiento y, por ende, sobre la seguridad jurídica. De las dificultades de localización del derecho apli-

53 O las 83 y 91 disposiciones adicionales y 34 y 31 finales, también respectivamente, de las Leyes de presupuestos para 2012 y 2013, Leyes $2 / 1012$ y 17/2012.

54 Puede verse también la Ley 16/2012, de 27 de diciembre, por la que se adoptan diversas medidas tributarias dirigidas a la consolidación de las finanzas públicas y al impulso de la actividad económica, que modifica al menos 26 normas con rango de ley.

55 Con lo cual resulta un sarcasmo el tenor del artículo 4.9 de la Ley, según el cual «los poderes públicos procurarán el mantenimiento de un marco normativo estable, transparente y lo más simplificado posible, fácilmente accesible por los ciudadanos y agentes económicos, posibilitando el conocimiento rápido y sencillo de la normativa vigente que resulte de aplicación».

56 A los ya citados cabe añadir, por todos, L. M CAZORLA PRIETO (Las llamadas leyes de acompañamiento presupuestario. Sus problemas de constitucionalidad, Marcial Pons, Madrid, 1998) e I. M. GIMÉNEZ SÁNCHEZ («Las leyes de acompañamiento y el problema de las "leyes ómnibus”», cit., págs. 525 y ss.).

57 Consejo General del Poder Judicial, Consejo de Estado, Consejo Consultivo de la Generalidad de Cataluña (véase el dictamen 210, de 28 de diciembre de 1998; sin perjuicio de postular un examen casuístico del contenido de la ley, y de afirmar que ser «expresión de una técnica legislativa peligrosa no la invalida, pues la técnica legislativa no es susceptible de ser equiparada al Derecho constitucional», declara que los operadores jurídicos pueden verse afectados por una incertidumbre insuperable, por el hecho de ser normas «aglomeradas en cuanto a su contenido». "No creemos...que las "leyes de acompañamiento" deban ser globalmente y en su conjunto rechazadas por el sólo hecho de tratarse de una especie de totum revolutum o de “cajón de sastre” en el que prácticamente cabe todo. Esto, ciertamente, es expresión de una técnica legislativa 
cable que provocan vamos a dar un solo ejemplo: el volumen de normas modificadas por estas leyes no permite que la referencia a las mismas figure en su título, lo que constituye un primer elemento de inseguridad. Por recordar una normativa especialmente sensible para la seguridad jurídica, pueden contabilizarse más de veinticinco leyes modificadoras del Código Penal desde su aprobación por Ley Orgánica 10/1995, de las cuales al menos diez no indican en su título que contienen tal modificación. Si en el título no figura al menos tal referencia y, a ser posible, a qué materia afecta la modificación, es difícil concluir que se cumple estrictamente con la exigencia de certeza sobre el derecho aplicable ${ }^{58}$.

Ahora que se habla tanto de transparencia, no hay nada más opaco que una ley ómnibus.

\section{Anterior doctrina del Tribunal Constitucional}

Solo la Ley de Presupuestos había sido objeto en nuestro país de una delimitación de su contenido material (que afecta a la iniciativa y a las enmiendas) por el Tribunal Constitucional, sobre la base del artículo 134 de la Constitución, pero también del principio de seguridad jurídica proclamado en el artículo $9.3^{59}$.

Son conocidas las peripecias que ha experimentado la llamada Ley de acompañamiento de los presupuestos. Recordemos que el fenómeno de leyes ómnibus de este tipo se inicia con las leyes de Presupuestos Generales del Estado, en las que fueron incluyéndose preceptos modificadores de cualquier materia legislativa, excepto la creación de tributos prohibida por el artículo 134.7 de la Constitución. En la sentencia 76/1992, el Tribunal Constitucional impone la limitación material del contenido de la Ley de

peligrosa y, tal vez, poco recomendable, pero en sí misma no es inconstitucional, ya que la técnica legislativa no es susceptible de ser equiparada al Derecho constitucional» F 2.8).

58 Dice A. V. SEMPERE, «El escondite jurídico», cit., pág. 3: «No se trata de que se lleven todos estos supuestos al Tribunal Constitucional (aunque un pronunciamiento suyo sobre alguno de los temas referidos sería bien recibido), sino de que se abandone esa práctica detestable consistente en aprovechar cualquier envoltorio normativo para incorporarle los contenidos más insospechados. Si las normas poseen una rúbrica es por y para algo, pues en caso contrario bastaría con numerarlas y fecharlas corriendo los destinatarios con la carga de su lectura (o conocimiento) íntegro».

59 La limitación material del contenido resulta «una exigencia del principio de seguridad jurídica constitucionalmente garantizado (art. 9.3 CE), esto es, la certeza del Derecho que exige que una Ley de contenido constitucionalmente definido, como es la Ley de Presupuestos Generales, no contenga más disposiciones que las que corresponden a su función constitucional (arts. 66.2 y 134.2 CE), «debido a la incertidumbre que una regulación de este tipo origina»» (por todas, STC 174/1998 FJ 6). Como es sabido, la doctrina constitucional sobre la Ley de Presupuestos exige el cumplimiento de dos requisitos para la inclusión del llamado «contenido posible y eventual» junto al mínimo e indisponible: la directa relación con este último o con los criterios de política económica general que lo sustenta, y la justificación de la inclusión de la materia conexa (así en STC 76/1992, FJ 4). Cumplidos ambos requisitos, la inclusión de una norma con vocación de permanencia en la citada Ley ha sido considerada «una mera cuestión de técnica legislativa, aun cuando determinadas regulaciones llevadas a cabo en la Ley de Presupuestos encuentren su sede normativa natural y técnicamente más correcta en las disposiciones generales que disciplinan los regímenes jurídicos a los que se refieren» (SSTC 32/2000, FJ 6 y 109/2001, FJ 6). Puede verse un resumen de la doctrina sobre los límites materiales a la Ley de presupuestos en la reciente sentencia 9/2013, de 28 de enero. Véase también J. A. Toscano Ortega, Límites constitucionales al contenido material de las Leyes de Presupuestos del Estado, Congreso de los Diputados, Madrid, 2005. 
Presupuestos, lo que tuvo como consecuencia que se abandonara la inclusión en ella de las normas cuya modificación se consideraba necesaria para el ejercicio siguiente, que pasarían a integrar las conocidas, aquí y en otros países, como «leyes de acompañamiento presupuestario», inauguradas por la Ley 22/1993, de 29 de diciembre, de Medidas fiscales, de reforma de la función pública y de la protección por desempleo. Estas leyes de medidas, criticadas —e impugnadas - por el Partido Socialista mientras estuvo en la oposición de 1996 a 2004, desaparecen con el cambio de mayoría parlamentaria en esta última fecha, siendo la última la Ley $62 / 2003^{60}$.

En la sentencia 65/1990 FJ 3, el Tribunal establece la conexión entre el contenido material de la Ley de Presupuestos y el principio de seguridad jurídica, afirmando que no «cabe descartar que la regulación injustificada de una materia no estrictamente presupuestaria mediante las Leyes anuales de Presupuestos pueda, por la incertidumbre que origina, afectar al principio de seguridad jurídica ${ }^{61} »$. Este razonamiento sería perfectamente extrapolable, en lo que a la lesión de la seguridad jurídica se refiere por la incertidumbre que originan, a otras leyes, y no sólo de contenido constitucionalmente definido.

Sin embargo, la sentencia 332/2005 FJ 17 despacha como habitual en los decretosleyes su contenido heterogéneo, que no considera causante de una confusión normativa lesiva para la seguridad jurídica «teniendo en cuenta el contenido habitualmente heterogéneo de los Decretos-leyes, los medios existentes en la actualidad para hallar el Derecho vigente en cada momento, y que dicha reforma se integra en un capítulo autónomo del Decreto-ley impugnado» ${ }^{62}$. A estas afirmaciones podríamos contraponer la distinción entre contenido definido, transversalidad y preceptos intrusos que desarrollaremos más adelante.

Tampoco se ha considerado causa de invalidez la inclusión de una norma con vocación de permanencia en la Ley de Presupuestos (por todas, STC 109/2001, FJ 6) ${ }^{63}$.

60 Un contenido más mesurado — limitado al ámbito tributario aunque modifica más de veinte leyes_ ofrece, de nuevo tras un cambio de mayoría, la citada Ley 16/2012, de 27 de diciembre, por la que se adoptan diversas medidas tributarias dirigidas a la consolidación de las finanzas públicas y al impulso de la actividad económica.

61 Conexión reiterada en otras sentencias como la 32/2000 FJ 5: «Tal limitación [del contenido de la Ley de Presupuestos] es, además, una exigencia del principio de seguridad jurídica constitucionalmente garantizado (art. 9.3 C.E.). esto es, de la certeza del Derecho que exige que una Ley de contenido constitucionalmente definido, como es la Ley de Presupuestos Generales del Estado, no contenga más disposiciones que las que guardan correspondencia con su función constitucional (arts. 66.2 y 134.2 C.E.), debido a la incertidumbre que una regulación de este tipo indudablemente origina (SSTC 65/1990, 76/1992, 116, 178 y 195/1994, 61/1997, 174 y 203/1998)».

62 No se consideró causante de una confusión normativa lesiva del principio de seguridad jurídica reformar el régimen jurídico de la inspección técnica de vehículos (ITV) a través de un Decreto ley relativo a la liberalización de las telecomunicaciones (Real Decreto Ley 7/2000, de 23 de junio, de medidas urgentes en el sector de las telecomunicaciones).

63 «Es nuestra doctrina que nada impide —en principio - la inclusión en una Ley de Presupuestos de una norma con vocación de permanencia (por todas, SSTC 65/1990, de 5 de abril, FJ 3; 32/2000, de 3 de febrero, FJ 6; y 274/2000, de 15 de noviembre, FJ 4), aun cuando determinadas regulaciones llevadas a cabo en la Ley de Presupuestos encuentren su sede normativa natural y técnicamente más correcta en las disposiciones generales que disciplinan los regímenes jurídicos a los que se refieren (STC 32/2000, de 3 de febrero, FJ 6). Por este motivo, y sin entrar en cuestiones de técnica legislativa, y dado que «nuestro control de constitucionalidad no es un juicio sobre la cualidad técnica del ordenamiento jurídico, ni sobre la oportunidad de las opciones adoptadas por el legislador» (STC 32/2000, de 3 de febrero, FJ 6), no cabe negar a la norma cuestionada una repercusión directa sobre los ingresos de la Seguridad Social y, por ende, una legitimación 


\section{Doctrina del Tribunal Constitucional sobre las leyes de contenido heterogéneo}

La sentencia 136/2011 presenta la relevancia de sentar doctrina sobre las leyes de medidas como leyes de contenido heterogéneo, en definitiva sobre las leyes ómnibus. Una doctrina que ha sido claramente resumida en la sentencia 176/2011 (FJ 2) (también luego en la STC 209/2012, FJ 2), según la cual los motivos de inconstitucionalidad esgrimidos y la respuesta del Tribunal eran los siguientes (los subrayados son nuestros):

«a) La imposibilidad constitucional de la existencia de una ley ordinaria que, con carácter anual y contenido impredecible, opere sobre la totalidad del ordenamiento jurídico, respecto de lo que concluimos que "ningún óbice existe desde el punto de vista constitucional que impida o limite la incorporación a un solo texto legislativo, para su tramitación conjunta en un solo procedimiento, de multitud de medidas normativas de carácter heterogéneo" (STC 136/2011, de 13 de septiembre, FJ 3). b) La alteración del sistema de fuentes, con relación a la cual señalamos que su contenido heterogéneo "no modifica su naturaleza de ley ordinaria, ni, por ende, altera su relación con las demás normas que integran el Ordenamiento jurídico" por lo que no alteran el sistema de fuentes establecido por nuestra Constitución (STC 136/2011, de 13 de septiembre, FJ 4). c) La infracción del principio democrático, el pluralismo político, la separación de poderes y los derechos de las minorías, sobre la que concluimos que el principio democrático consagrado por nuestra Constitución (art. 1.1) impone que la formación de la voluntad de las Cortes Generales se articule «a través de un procedimiento cuyos rasgos estructurales ha prescrito el texto constitucional» y en el que opera el "principio mayoritario y, por tanto, la consecución de una determinada mayoría como fórmula para la integración de voluntades concurrentes" (STC 136/2011, de 13 de septiembre, FJ 5). d) La violación del derecho de enmienda por haberse añadido, en ambas Cámaras, importantes enmiendas aprobadas con el apoyo del grupo mayoritario, con referencia a la que señalamos que, siendo cierto que en el ejercicio del derecho de enmienda al articulado debe respetarse una "conexión mínima de homogeneidad con el texto enmendado", so pena de afectar, de modo contrario a la Constitución, tanto al derecho del autor de la iniciativa (art. $87 \mathrm{CE}$ ), como al carácter instrumental del procedimiento legislativo (art. 66.2 CE) y, en consecuencia, a la función y fines asignados al ejercicio de la potestad legislativa por las Cámaras, provocando un vicio en el desarrollo del citado procedimiento que podría alcanzar relevancia constitucional, si alterase de forma sustancial el proceso de formación de voluntad en el seno de las Cámara, sin embargo, los Diputados recurrentes no habían impugnado precepto alguno de la ley controvertida que eventualmente pudiera haber adolecido del defecto denunciado. Esa misma carencia de impugnación concurre en este caso, no siendo función de este Tribunal Constitucional la de investigar el contenido de la ley impugnada a la búsqueda de los concretos preceptos respecto de los cuales se hubiese podido producir la situación denunciada en la demanda (STC 136/2011, de 13 de

suficiente para servirse del vehículo de la Ley de Presupuestos». En la sentencia 32/2000, FJ 6 se afirma: «el criterio de temporalidad no resulta en principio determinante de la constitucionalidad o no de una norma como la cuestionada desde la perspectiva de su inclusión en una Ley de Presupuestos (STC 65/1990, FJ 3)». El Consejo de Estado se ha pronunciado en contra de la incidencia de la citada ley en regímenes jurídicos sustantivos. Véase F. RUBIO LLORENTE, «El papel del Consejo de Estado en el control de la calidad técnica de las normas», cit., págs. 34-35. 
septiembre, FJ 8). e) La infracción del principio de seguridad jurídica (art. 9.3 CE) al tratarse de una ley de contenido indefinido y sin objeto predeterminado, respecto de la que afirmamos que la norma impugnada tenía un objeto que, "aunque heterogéneo, está perfectamente delimitado en el momento de presentación del proyecto al Congreso de los Diputados, teniendo todos sus eventuales destinatarios (operadores jurídicos y ciudadanos) conocimiento del mismo mediante su publicación en el Diario Oficial de las Cortes Generales, como finalmente tienen conocimiento del texto definitivo mediante su inserción en el Boletín Oficial del Estado» (STC 136/2011, de 13 de septiembre, FJ 9), tal y como sucede en este caso. f) $\mathrm{Y}$, en fin, la infracción de una serie de reglas del procedimiento parlamentario, como que los antecedentes que se acompañaron al proyecto de ley no podían calificarse como tales, que se había delegado en una comisión legislativa permanente la aprobación del proyecto de ley cuando ello no era obligatorio, que la Comisión de Economía, Comercio y Hacienda, del Congreso de los Diputados, no había solicitado informes sobre cuestiones que eran competencia principal de otras comisiones, que habían intervenido Diputados de los distintos grupos parlamentarios que no eran miembros de la Comisión de Economía, Comercio y Hacienda sin que constase su sustitución formal o informal, y, en fin, que se había tramitado el proyecto de ley por el procedimiento de urgencia. Pues bien, estos vicios fueron rechazados no sólo por no haberse denunciado algunos de ellos ante la correspondiente Cámara sino, lo que es más importante, por no haberse acreditado que su alcance era de tal magnitud que hubiese alterado, "no de cualquier manera, sino de forma sustancial, el proceso de formación de la voluntad de una Cámara, habiendo afectado, en consecuencia, al ejercicio de la función representativa inherente al estatuto del parlamentario" (STC 136/2011, de 13 de septiembre, FJ 10), acreditación tampoco realizada ahora.»

En ambas sentencias (FJ 11 y 3, respectivamente) se rechaza también que se apliquen a las leyes de acompañamiento los límites que la Constitución prevé para las leyes de presupuestos generales del Estado en los artículos 134.2 y 7 de la Constitución: «debe afirmarse taxativamente que las limitaciones materiales y temporales a que el constituyente ha sometido el instrumento presupuestario sólo a éste se refieren, no pudiendo extrapolarse a otras disposiciones generales que, no siendo fruto de la actividad presupuestaria de las Cortes (art. $134 \mathrm{CE}$ ), son el resultado del ejercicio genérico de su actividad legislativa (art. 66.2 CE) (STC 136/2011, de 13 de septiembre, FJ 11)».

En cuanto a cuestiones nuevas planteadas en el recurso que da lugar a la sentencia 176/2012, la alegación de vicios de procedimiento legislativo por negativa de la Mesa a la reconsideración de los acuerdos de tramitación en la Comisión de Economía, Comercio y Hacienda y de no solicitar informe a otras comisiones, así como por tramitación en un solo punto del orden del día y debate conjunto de enmiendas de totalidad de devolución del Proyecto de ley de Presupuestos y el Proyecto de Ley de Medidas, el Tribunal insiste en que son actos de trámite insertos en un procedimiento parlamentario, cuya eventual inobservancia sólo podría alcanzar relevancia constitucional y, por tanto, viciar de inconstitucionalidad la ley resultante cuando esas inobservancias alterasen de modo sustancial el proceso de formación de voluntad de una Cámara. En este caso, no sólo los vicios citados no fueron denunciados ante la misma Cámara (salvo el de la decisión de atribuir a la Comisión de Economía, Comercio y Hacienda, el estudio del proyecto de ley, decisión ésta respecto de la que se solicitó su reconsideración), sino que, una vez más, los 
Diputados recurrentes se limitan a cuestionar de forma genérica determinadas decisiones de la Mesa del Congreso, sin un mínimo de argumentación que permita poner en cuestión sobre esta base la constitucionalidad de la totalidad de la ley impugnada ${ }^{64}$.

Por detenernos un poco más en el juicio a las leyes de acompañamiento como leyes de contenido heterogéneo, formulado en la STC 136/2011 al refutar el primer motivo de impugnación, el Tribunal Constitucional afirma (FJ 3) que la reprobación que hacen los recurrentes al uso de las leyes de medidas (como leyes ómnibus que modifican gran número de leyes) es un juicio de evidente valor político pero que no convierte a la norma per se en inconstitucional.

Los recurrentes alegaban que no es admisible el uso de cualquier técnica legislativa, so pena de infringir los principios democráticos (art. $1 \mathrm{CE}$ ) y de seguridad jurídica (art. 9.3). El Tribunal admite que el recurso a ese tipo de disposiciones legislativas, «dotadas de una gran heterogeneidad, tramitadas además por el procedimiento de urgencia, puede afectar en cierta manera al ejercicio efectivo del derecho a la participación política de los poderes estatuidos», pero que no se ha demostrado que esa afectación haya sido sustancial. «Por ello no puede imputarse a tal plasmación de la competencia legislativa de falta de legitimación democrática ni en su ejercicio ni en su resultado, razón por la cual, aunque la opción elegida pueda ser eventualmente criticable desde el punto de vista de la técnica jurídica, en modo alguno lo es desde la perspectiva constitucional».

El Tribunal reitera que las Cortes Generales, como titulares «de la potestad legislativa del Estado»(art. 66.2 de la Constitución), pueden legislar en principio sobre cualquier materia sin necesidad de poseer un título específico para ello, pero esta potestad tiene sus límites, derivados de la propia Constitución (STC 76/1983, FJ 4). Al igual que declaró que las leyes tienen que tender a la generalidad pero ello no impide con carácter excepcional la existencia de leyes singulares, afirma el Tribunal que «el dogma de la deseable homogeneidad de un texto legislativo no es obstáculo insalvable que impida al legislador dictar normas multisectoriales, pues tampoco existe en la Constitución precepto alguno, expreso o implícito, que impida

64 «Todo ello sin olvidar, como ya hemos tenido ocasión de señalar, «que no se puede confundir el ejercicio de una facultad con el cumplimiento de una obligación, para colegir del no ejercicio de aquélla por quien tiene la opción de acordar su cumplimiento, la inconstitucionalidad de la norma resultante del procedimiento legislativo» [STC 136/2011, de 13 de septiembre, FJ 10 c)].»

Finalmente, el Tribunal se ocupa de la retroactividad de una modificación de una norma tributaria, para concluir, aplicando su doctrina anterior, que «la norma cuestionada ha llevado a cabo, retroactivamente, una alteración en la determinación de la deuda tributaria del impuesto sobre la renta de las personas físicas sin la concurrencia de nítidas y cualificadas exigencias de interés general que justificasen el efecto retroactivo otorgado, lo que conduce a estimar que se ha producido la vulneración del principio de seguridad jurídica garantizado por el art. 9.3 de la Constitución y, en su consecuencia, a declarar la inconstitucionalidad y nulidad del párrafo primero de la disposición transitoria duodécima de la Ley 55/1999, de 29 de diciembre, de medidas fiscales, administrativas y del orden social». No obstante, la inconstitucionalidad que se declara afecta sólo a la aplicación retroactiva de la medida adoptada, que no a la medida misma, la cual no ha sido impugnada. Y por exigencia del principio de seguridad jurídica (art. 9.3 CE), se declara que únicamente han de considerarse situaciones susceptibles de ser revisadas con fundamento aquellas que, a la fecha de publicación de la misma, no hayan adquirido firmeza por haber sido impugnadas en tiempo y forma y no haber recaído todavía una resolución administrativa o judicial firme sobre las mismas (art. 40.1 de la Ley Orgánica del Tribunal Constitucional). 
que las leyes tengan un contenido heterogéneo», siendo el único límite en nuestro ordenamiento el previsto en la Ley Orgánica 3/1984, de 26 de marzo, reguladora de la iniciativa legislativa popular ${ }^{65}$. «Por tanto, aun aceptando que una ley como la impugnada puede ser expresión de una deficiente técnica legislativa, no por ello cabe inferir de modo necesario una infracción de la Constitución habida cuenta que el juicio de constitucionalidad que corresponde hacer a este Tribunal «no lo es de técnica legislativa» ${ }^{66}$ [SSTC 109/1987, de 29 de junio, FJ 3 c); y 195/1996, de 28 de noviembre, FJ 4], ni de «perfección técnica de las leyes» (SSTC 226/1993, de 8 de julio, FJ 4), pues nuestro control «nada tiene que ver con su depuración técnica» (SSTC 226/1993, de 8 de julio, FJ 5; y 195/1996, de 28 de noviembre, FJ 4). Como señala el Abogado del Estado, la Ley 50/1998 es una ley ordinaria que no está necesitada de ninguna previsión constitucional para ser dictada ni se ve constreñida tampoco por ningún mandato constitucional. En sentido similar, apunta el representante del Senado, la ley ordinaria, como ley que emana de las Cortes Generales, puede entrar a regular cualquier materia no expresamente asignada a otro tipo legislativo, y es que, del bloque de la constitucionalidad no se deriva ni impedimento alguno para que se puedan aprobar lo que califica como «leyes transversales», ni exigencia de ninguna clase que imponga que cada materia deba ser objeto de un proyecto independiente, dado que las formas de manifestarse la voluntad de las Cámaras sólo tendrán un carácter limitado cuando así se derive del propio texto constitucional.// En consecuencia, ningún óbice existe desde el punto de vista constitucional que impida o limite la incorporación a un solo texto legislativo, para su tramitación conjunta en un solo procedimiento, de multitud de medidas normativas de carácter heterogéneo».

Frente a esta doctrina, cobra especial relevancia el extenso voto particular discrepante del magistrado Aragón Reyes, que no podemos reproducir aquí, pero del que pueden destacarse algunas ideas:

Aragón fundamenta la inconstitucionalidad de la ley impugnada en la vulneración del principio democrático reconocido en el artículo 1.1 de la Constitución y de

65 «Descartada ya la existencia de prohibición alguna en el texto constitucional a la existencia de las leyes complejas [así denominábamos, por ejemplo, en la STC 126/1987, de 16 de julio, a la Ley 5/1983, de 29 de junio, de medidas urgentes en materia presupuestaria, financiera y tributaria, que contenía «normas relativas a las operaciones financieras del sector público, normas de contratación y normas tributarias» (FJ 5)], multisectoriales o de contenido heterogéneo, resta por determinar si existe algún límite a su uso o contenido, debiendo responderse a esta cuestión también de forma negativa, pues la Constitución no prevé que el principio de competencia o especialidad obligue a que sólo puedan aprobarse constitucionalmente normas homogéneas que se refieran a una materia concreta. A este respecto hay que señalar que no cabe duda de que sería una técnica más perfecta la de circunscribir el debate político de un proyecto de ley a una materia específica, lo que alentaría una mayor especialización del mismo y, posiblemente, una mejor pureza técnica del resultado. Sin embargo, los reparos que pudieran oponerse a la técnica de las leyes multisectoriales, por su referencia a un buen número de materias diferentes, no dejan de ser en muchas ocasiones otra cosa que una objeción de simple oportunidad, sin relevancia, por tanto, como juicio de constitucionalidad stricto sensu, tanto más cuanto que una y otra norma legal son obra del legislador democrático».

66 Véase, en el mismo sentido, la opinión del Consejo Consultivo de la Generalidad de Cataluña recogido en nota 57 . 
su proyección sobre el procedimiento legislativo. Entiende que el recurso ofrecía al Tribunal Constitucional la ocasión de poner coto a la práctica legislativa de las conocidas como «leyes de acompañamiento». El Tribunal Constitucional podía y debía, en opinión de Aragón, declarar inconstitucional esa práctica viciada, ya que le corresponde preservar el correcto funcionamiento del sistema de producción normativa querido por la Constitución. Las «leyes de acompañamiento» anuales son leyes cuyos rasgos principales ponen de manifiesto la perversión legislativa que entrañan: se trata de leyes cuyo calendario de tramitación se hace coincidir con el del proyecto de Ley de presupuestos generales del Estado para cada ejercicio, que se caracterizan por llevar a cabo, de manera asistemática, numerosas modificaciones normativas con vocación de permanencia que versan sobre las materias más dispares del ordenamiento jurídico (en el caso de la Ley 50/1998 se modificaron 76 leyes, 7 decretos legislativos y 6 decretos leyes); buen número de esas modificaciones se introdujeron a lo largo del procedimiento legislativo a través de enmiendas (el proyecto de ley afectaba «sólo» a 34 normas de rango legal, y al final del proceso parlamentario acabó afectando a 89).

La heterogeneidad y ausencia de sistema de este tipo de leyes provoca un innegable efecto descodificador del ordenamiento jurídico de tal magnitud (reformas de 89 textos de rango legal sobre las más variadas y distantes materias) que origina una evidente incertidumbre sobre la normativa vigente, lo que representa un riesgo, sin duda, para la seguridad jurídica garantizada por el art. 9.3 CE. No obstante, estos defectos, que fomentan sin duda la inseguridad, no suponen ineluctablemente su realización y en tal sentido no pueden erigirse, por sí solos, en causa de inconstitucionalidad de la ley. Sí que ponen de manifiesto, desde luego, una deplorable técnica legislativa, pero, como sostiene la Sentencia de la que discrepa (no en este punto), el juicio de constitucionalidad que corresponde realizar a este Tribunal no puede versar sobre la técnica legislativa o la perfección técnica de las leyes (aunque tampoco está de más, a su juicio, resaltar que la calidad de las leyes debiera constituir un objetivo primordial del legislador y más todavía del legislador democrático). La razón más fuerte y decisiva de la inconstitucionalidad de la ley impugnada, reside, a su juicio, en la vulneración del principio democrático (art. 1.1 CE), como manifestación de la soberanía popular (arts. 1.2 y 66.1 CE y STC 119/1995, de 17 de julio, FJ 3), y de su proyección sobre el procedimiento legislativo (arts. 66.2, 89.2 y $90 \mathrm{CE}$, en particular). Se trata de un acabado (mal) ejemplo de desvirtuación de lo previsto en art. 66.2 CE, que atribuye a las Cortes Generales, representantes del pueblo español, la potestad legislativa del Estado, en cuanto que desnaturaliza la función legislativa de las Cortes, así como la concepción constitucional de la ley (ínsita en los arts. 1.1 y 2 y 66.1 y 2 CE) como expresión de la voluntad popular.

La función legislativa de las Cortes Generales (art. 66.2 CE) se identifica con un determinado procedimiento parlamentario: el procedimiento legislativo. Cierto es que la decisión final que da lugar a la Ley como producto normativo formal queda en manos de la mayoría parlamentaria (sostén del Gobierno que dirige la acción política de cada legislatura), pero ello no desvirtúa el hecho de que el procedimiento legislativo garantiza a la minoría su derecho al debate y a la presentación de enmiendas, que es lo relevante a los efectos que aquí interesan.

«Queda así despejado el equívoco en el que incurre en su fundamento jurídico 5 la Sentencia de la que discrepo, al confundir principio democrático y principio mayoritario. No es dudoso que nuestra Constitución ha instaurado una democracia basada en el juego de las mayorías, previendo sólo para supuestos tasados y excepcionales una democracia de acuerdo basada en mayorías cualificadas o reforzadas, como este Tribunal tuvo oca- 
sión de advertir tempranamente ya en su STC 5/1981, de 13 de febrero, FJ 21. Pero, para no incurrir en errores conceptuales elementales, es necesario distinguir dos planos diferentes: por un lado, el de la adopción de decisiones parlamentarias, que es donde cabalmente rige el principio mayoritario al que se refiere nuestra doctrina; por otro, el del procedimiento deliberativo previo a la adopción de la decisión o acuerdo parlamentario, que es donde tiene su cabal asiento el principio de pluralismo democrático (art. 1.1 CE) como manifestación de la participación política de la minoría». [...]

«Resulta así que, constitucionalmente, no puede tener valor de ley cualquier decisión adoptada por el Parlamento con este nombre. Como hemos tenido ocasión de señalar, "las Cortes Generales, como titulares de la potestad legislativa del Estado (art. 66.2 $\mathrm{CE}$ ), pueden legislar en principio sobre cualquier materia sin necesidad de poseer un título específico para ello, pero esa potestad tiene sus límites, derivados de la propia Constitución" (STC 76/1983, de 5 de agosto, FJ 4). Estos límites son tanto sustantivos como formales, de suerte que la ley no puede entrar en contradicción con normas materiales de la Constitución, ni tampoco con normas o principios estructurales expresos o deducibles de nuestro sistema constitucional parlamentario y democrático. Si se traspasan esos límites, este Tribunal está llamado a depurar y expulsar del ordenamiento jurídico la ley inconstitucional, tanto por motivos formales como materiales, garantizando la primacía de la Constitución (art. 27.1 CE), mediante los procesos de declaración de inconstitucionalidad de las leyes (arts. 161 a $164 \mathrm{CE}$ y arts. 27 y ss. LOTC)».

En su opinión, la elaboración de la Ley 50/1998, de 30 de diciembre, de medidas fiscales, administrativas y del orden social, no responde a las exigencias del concepto constitucional de ley señalado, como decisión parlamentaria adoptada por las Cortes Generales a través de un procedimiento legislativo de deliberación racional que responde a las exigencias del principio democrático en cuanto a la participación política de la minoría. «En efecto, la Ley 50/1998 es una "ley de acompañamiento” que, debido a las peculiares características que se advierten en su tramitación parlamentaria, resulta contraria a la Constitución (y a los Reglamentos de las Cámaras, que integran el bloque de la constitucionalidad a los efectos que nos ocupan y que, en consecuencia, se erigen en canon de control de la ley) por las restricciones ilegítimas que ha supuesto para la potestad legislativa de las Cortes Generales (art. 66.2 CE)»:

- Enmiendas que encubren verdaderas iniciativas legislativas. La admisión como enmiendas de textos que no guardan relación material alguna con la iniciativa legislativa a enmendar, afecta al núcleo de la función representativa de los Diputados y lesiona su derecho al ejercicio del cargo parlamentario, garantizado por el art. 23.2 CE y conectado con el principio democrático (art. 1.1 CE) ${ }^{67}$.

- Estos vicios han alterado de modo sustancial el proceso de formación de voluntad en el seno de las Cámaras, estando el Tribunal obligado a indagar qué enmiendas encubren verdaderos supuestos de iniciativa legislativa.

67 Los Diputados vieron «restringidas sus posibilidades de deliberación en el debate parlamentario, haciendo imposible la presentación de alternativas y su defensa, que constituyen la esencia de su función representativa como Diputados, resultando así vulnerado su derecho fundamental al ejercicio del cargo parlamentario (art. 23.2 CE)». La introducción en el Senado de enmiendas que no guardan relación de homogeneidad material ni textual alguna con el proyecto de ley remitido por el Congreso, infringe además los arts. 89.2 y 90 CE, restringe los derechos del grupo parlamentario minoritario y la capacidad de intervención de los diputados. 
— El debate ante una sola Comisión menoscaba el principio de especialidad parlamentaria como proyección de la exigencia de deliberación racional, a su vez manifestación del pluralismo democrático (art. 1.1 y 66 CE).

- Las pretendidas exigencias de la realidad política y la urgencia de las reformas no justifican la inaceptable práctica de admitir enmiendas que encubren iniciativas legislativas, no sólo porque no es admisible constituir la patología en paradigma, sino porque, además, nuestro ordenamiento prevé diversas soluciones: presentación conjunta de proposiciones de ley por parte de los grupos políticos parlamentarios, procedimientos de urgencia y lectura única, aprobación de decretos leyes. ${ }^{68}$

Aunque Aragón considera que estas razones debieron conducir a la declaración de inconstitucionalidad de dicha Ley, entiende que con efectos no anulatorios, teniendo en cuenta no sólo el hecho de la eventual derogación o modificación de algunos preceptos contenidos en dicha Ley a la fecha de pronunciarse esta Sentencia, sino también la necesidad de evitar el vacío normativo que se produciría en diversos sectores del ordenamiento por la nulidad de la ley declarada inconstitucional ${ }^{69}$. Esta desvinculación entre inconstitucionalidad y nulidad debería venir acompañada de una expresa llamada de atención al legislador ${ }^{70}$ para que en lo sucesivo se abstenga de volver a utilizar la técnica legislativa de las llamadas «leyes de acompañamiento», con la advertencia de que la utilización futura de este tipo de leyes será declarada inconstitucional y nula, con efectos ex tunc ${ }^{71}$.

68 «En efecto, no puede entenderse que este tipo de leyes — de las que las llamadas "leyes de acompañamiento" no son más que un significativo ejemplo - tengan funcionalidad alguna en nuestro sistema constitucional. Resultaría indefendible sostener que cada año el Gobierno pueda llevar a cabo una especie de revisión general o aggiornamento de casi todo el ordenamiento jurídico (o de numerosos sectores del mismo) a través de instrumentos normativos que, en expresiones sumamente gráficas que han hecho fortuna incluso entre la doctrina científica, son conocidos como "leyes escoba", "leyes ómnibus", o "leyes paraguas". Ni las razones de urgencia que pueden sobrevenir en determinadas circunstancias ni las necesidades coyunturales de la acción política pueden ser admitidas como argumento para cometer un fraude al procedimiento legislativo parlamentario y, por tanto, una burla a la Constitución.///Por eso, entender que puede ponerse en marcha, en un solo acto, una iniciativa legislativa no ya de contenido plural, sino extraordinariamente multiforme y asistemático, que culmina al final en una ley donde tales características acaban acentuándose mucho más; no reaccionar ante la subversión del procedimiento legislativo que supone despreciar la existencia de comisiones legislativas permanentes especializadas, y, al mismo tiempo, elaborar con gran precipitación y escaso debate reformas legislativas tan relevantes como sumamente heterogéneas; admitir un uso torticero del derecho de enmienda, aceptando que puedan calificarse como enmiendas y tramitarse (y aprobarse) como tales unos textos que, en realidad, encubren verdaderas iniciativas legislativas; es decir, convalidar la deforme criatura jurídica que han supuesto las llamadas "leyes de acompañamiento", significa, a mi juicio, dar por buena la degradación de la potestad legislativa y de la ley, con olvido de la función crucial que las Cámaras Legislativas desempeñan, esto es, con grave quebranto de las fundamentales reglas de juego de la democracia parlamentaria, conforme he dejado razonado a lo largo del presente Voto».

69 Esta solución, añadimos nosotros, resolvería los posibles reparos del Tribunal Constitucional ante la adopción de una sentencia de efectos devastadores sobre el ordenamiento por anular diez años después centenares de preceptos de leyes que se cuentan por decenas.

70 Un serio aviso al legislador reclamábamos en P. García-Escudero Márquez, Técnica legislativa y seguridad jurídica, cit., pág. 158.

71 Frente a este voto particular, el Magistrado Ortega Álvarez formula otro concurrente, en el que discrepa únicamente en la consideración que se hace respecto de la norma enjuiciada, asumiendo una crítica, aún potencial, de su calidad técnica. En efecto, por dos veces aparece esta crítica en el fundamento jurídico 3 , 


\section{Crítica de las sentencias}

Algunos comentarios a la doctrina sentada. Existen, obviamente, puntos de coincidencia. Estoy de acuerdo en que ha de respetarse la libertad de configuración del legislador, que es amplia, y que el procedimiento de tramitación de la ley impugnada, y en general de las leyes de contenido heterogéneo, se ajusta a lo constitucional y reglamentariamente establecido. Los motivos procedimentales alegados no son suficientes para declarar la inconstitucionalidad. Por ejemplo, el argumento de la especialidad de las comisiones no se sostiene, teniendo en cuenta la flexibilidad con que los Reglamentos de las Cámaras contemplan la sustitución de sus miembros, que permite contar con ponentes especialistas, aunque sean miembros de otra Comisión.

Son dos, sin embargo, los puntos en los que creo que puede centrarse la crítica. El primero es la concepción reiteradamente expuesta por el Tribunal Constitucional del principio de publicidad de las normas, con el que empezaré, por ser el más breve.

\section{a) Publicación y publicidad}

La publicidad de las normas, garantizada por la Constitución, es una exigencia del Estado de derecho y proporciona a todos, como dice Sainz Moreno ${ }^{72}$, la seguridad de que no hay más normas escritas que las publicadas y de que su contenido es exactamente el publicado en el Boletín Oficial. Observemos que el artículo 9.3 alude a la «publicidad» y no a la «publicación» de las normas. En efecto, aunque se da por supuesto que la publicidad — que excluye su carácter secreto o reservado— se produce mediante la publicación en el Diario Oficial, puede haber ocasiones en que ésta no sea suficiente para alcanzar el requisito de publicidad.

donde se señala que «aunque la opción elegida pueda ser eventualmente criticable desde el punto de la técnica jurídica...»y, más adelante, que «aun aceptando que una ley como la impugnada puede ser expresión de una deficiente técnica legislativa». En su opinión, tal crítica no debería haber figurado en el texto de la Sentencia. En primer lugar porque, tal como recoge el texto aprobado, «el juicio de constitucionalidad que corresponde hacer a este Tribunal "no lo es de la técnica legislativa"». En consecuencia, si no les corresponde un juicio sobre la técnica legislativa, sobra, a su juicio, la expresada opinión crítica antes doblemente citada. «Los retruécanos generan una suerte de ambigüedad en la expresión que es inadecuada en nuestras Sentencias». Pero además, en lo que implica la asunción de su potencialidad de mala técnica, cree que es en sí mismo rechazable. «La complejidad política, social y económica de una sociedad desarrollada, tiene como natural correlación la existencia de un ordenamiento extenso y complejo. A su vez, los ritmos que gobiernan este tipo de sociedad dotan a muchas de sus normas de un contenido temporal, para adecuarse a las situaciones cambiantes. Por ello, las leyes transversales como la aquí enjuiciada son una respuesta parlamentaria a este tipo de realidad que es propia de nuestra época. Respuesta, que, además, dota de las garantías de la tramitación parlamentaria alos supuestos de cambio normativo, que de otro modo irían posiblemente por la técnica del decreto-ley. De aquí que la técnica de la transversalidad es la adecuada a la finalidad del legislador de abordar temporalmente la puesta al día de una serie heterogénea de leyes. Finalidad que, como es obvio, no corresponde enjuiciar, ni siquiera en términos de mera opinión a este Tribunal». Puedo compartir la eventual necesidad de dictar leyes transversales, no en que en ellas quepa cualquier norma ajena a su objeto.

72 F. SÁINZ MORENO, «Técnica normativa», en Enciclopedia Jurídica Básica, Civitas, Madrid, 1995, tomo IV, pág. 6488. 
No obstante, el Tribunal Constitucional parece dar por supuesta la equivalencia de ambos términos, como se deduce del resumen de su doctrina que contiene la sentencia 90/2009, FJ 5:

«Y no se le puede hacer ningún reproche porque esta disposición, como es común requisito de toda norma legal, ha sido objeto de publicación en el Boletín Oficial del Estado..., habiéndose respetado, entonces, el principio de publicidad que consagra el art. 9.3. En efecto, el principio de publicidad, como elemento inherente al principio de seguridad jurídica (por todas, SSTC 104/2000, de 13 de abril, FJ 7; y 235/2000, de 5 de octubre FJ 8), constituye una garantía básica del Ordenamiento jurídico que implica la necesidad de que las normas sean dadas a conocer públicamente mediante su inclusión en los boletines oficiales correspondientes antes de que pueda exigirse su cumplimiento general. Esta garantía «aparece como consecuencia ineluctable de la proclamación de España como un Estado de Derecho, y se encuentra en íntima relación con el principio de seguridad jurídica consagrado en el mismo art. 9.3 CE, pues sólo podrán asegurarse las posiciones jurídicas de los ciudadanos, la posibilidad de éstos de ejercer y defender sus derechos, y la efectiva sujeción de los ciudadanos y los poderes públicos al ordenamiento jurídico, si los destinatarios de las normas tienen una efectiva oportunidad de conocerlas en cuanto tales normas, mediante un instrumento de difusión general que dé fe de su existencia y contenido, por lo que resultarán evidentemente contrarias al principio de publicidad aquellas normas que fueran de imposible o muy difícil conocimiento» (SSTC 179/1989, de 2 de noviembre, FJ 3; y 3/2003, de 16 de enero, FJ 10).»

Recordemos que la publicación no excluye otras formas de publicidad, que buscan que esta sea realmente efectiva. No debe olvidarse que el destinatario de las leyes, el obligado a cumplirlas, es el ciudadano, por mucho que haya aplicadores del derecho y operadores jurídicos. Las leyes se dirigen a obtener unos resultados, para los que es esencial su cumplimiento; en la medida en que esa obtención depende de los ciudadanos, es fundamental que estos conozcan la ley en primer lugar, comprendan su alcance y sentido y la acepten ${ }^{73}$. Sólo así la cumplirán. Si los afectados no conocen las leyes, difícilmente podrán cumplirlas. Por tanto, además de la claridad en el lenguaje, el conocimiento y la comprensión de una ley nueva pueden requerir de su divulgación y de su explicación a los ciudadanos.

Hemos reclamado la publicación consolidada de las leyes con carácter oficial, que incorpore correcciones de errores, modificaciones, derogaciones o anulaciones de preceptos por el Tribunal Constitucional ${ }^{74}$, como impone algún texto constitucional: el artículo 158 de la Constitución de Colombia, que tan sabiamente exige la homogeneidad en el contenido y las enmiendas de los proyectos de ley, establece: «La ley que sea objeto de reforma parcial se publicará en un solo texto que incorpore las modificaciones aprobadas $\gg^{75}$.

73 Cuando el legislador, y sobre todo el Gobierno, impulsor y ejecutor de la iniciativa legislativa, desea realmente su cumplimiento, se preocupa de publicitar el nuevo régimen establecido en la ley por otros medios. Piénsese en la publicidad en medios de comunicación de todo tipo que precedió a la entrada en vigor del carnet de conducir por puntos.

74 P. GARCÍA-ESCUDERO MÁRQUEZ, «Objetivo: mejorar la calidad de las leyes. Cinco propuestas de técnica legislativa», Revista de las Cortes Generales, n 80, 2010, pág. 97 y ss.

75 Entre nosotros, un propósito como el incluido en el artículo 6.1 de la hoy derogada Ley 1/1998, de derechos y garantías de los contribuyentes, según el cual «El Ministerio de Economía y Hacienda acordará 
Como dice Martin Kriele ${ }^{76}$ en la última de sus «máximas para el arte de legislar», debe asegurarse que las leyes se transmiten al pueblo. No basta con la publicidad formal, el pueblo ha de recibir suficiente información sobre las leyes y sobre los fines que con ellas se persiguen. Sólo si ese conocimiento efectivo es posible, se cumplirán los principios constitucionales de publicidad de las normas y seguridad jurídica.

Así lo ha expresado el Tribunal Constitucional en la sentencia 179/1989 FJ $3^{77}$, cuando se refiere — aun aludiendo a la publicación oficial — a la efectiva oportunidad de conocer las normas en cuanto tales, «por lo que resultarán evidentemente contrarias al principio de publicidad aquellas normas que fueran de imposible o muy difícil conocimiento».

Creo que alguno de los casos que he expuesto de preceptos intrusos o de preceptos escondidos, de los que no da noticia el título de la ley ni se corresponden con su contenido expreso, pueden quebrar el principio de publicidad constitucionalmente exigido. Sin embargo, el Tribunal Constitucional, en la sentencia 136/2011 (FJ 9), reitera que el requisito de publicidad se ha cumplido con la publicación de la disposición impugnada en el BOE, «habiéndose respetado, entonces el principio de publicidad que consagra el art. 9.3, y no siendo posible entender, en consecuencia, que dicha publicación no basta para el conocimiento formal de las disposiciones que la norma publicada incorpora» ${ }^{78}$. Es esta una concepción excesivamente formalista de la publicidad que tal vez algún día pueda ser revisada.

y ordenará la publicación el primer trimestre de cada ejercicio de los textos actualizados de las leyes y reales decretos en materia tributaria en los que se hayan producido variaciones respecto de los textos vigentes en el ejercicio precedente. Asimismo, ordenará la publicación en igual plazo y forma de una relación de todas las disposiciones tributarias que se hayan aprobado en dicho ejercicio», no parece que se haya cumplido, al menos de forma suficientemente conocida y accesible para el ciudadano. Derogada esta norma por la Ley 58/2003, General Tributaria, sus artículos 85 y 86 introducen una sutil variación ante — suponemos- el incumplimiento de la norma anterior: la obligación referida a una publicación — que cabía entender oficial— de los textos actualizados no se exige ya, sustituida por unas referencias más vagas a que el deber de la Administración de prestar a los obligados tributarios información y asistencia acerca de sus derechos y obligaciones, se hará, entre otras actuaciones, a través de la publicación de textos actualizados de las normas tributarias, así como de la doctrina administrativa de mayor trascendencia, y por la declaración de que «el Ministerio de Hacienda difundirá por cualquier medio, durante el primer trimestre del año, los textos actualizados de las normas estatales con rango de ley y real decreto en materia tributaria en los que se hayan producido variaciones respecto de los textos vigentes en el año precedente, así como una relación de las disposiciones tributarias que se hayan aprobado en dicho año». Se rebaja así obviamente la aportación a la seguridad jurídica en el conocimiento del derecho vigente que introducía el precepto anterior. Hay que reconocer, no obstante, que la página web del Ministerio de Hacienda y Administraciones Públicas contiene un apartado «Normativa y doctrina» en el que —esperamos_ se realizan las actualizaciones oportunas.

76 M. KRIELE, «Máximas para el arte de legislar», en III Jornadas de Derecho Parlamentario. La función legislativa de los parlamentos y la técnica de legislar, Congreso de los Diputados, Madrid, 2000, págs. 40 y ss.

77 También en SSTC 3/2003 FJ 10, 90/2009 FJ 5 y 136/2011 FJ 9.

78 Más aún, al referirse a la delimitación del contenido de la iniciativa — recordemos que niega su carácter indefinido - en el momento de la presentación del proyecto al Congreso de los Diputados, afirma que todos sus eventuales destinatarios (operadores jurídicos y ciudadanos) tenían «conocimiento del mismo mediante su publicación en el "Diario Oficial de las Cortes Generales" [sic], como finalmente tienen conocimiento del texto definitivo mediante su inserción en el Boletín Oficial del Estado» (SSTC 136/2011 FJ 9 y 176/2011 FJ 2). 
b) Preceptos intrusos en leyes de contenido heterogéneo. Una puntualización de compromiso que permite seguir avanzando

La síntesis de la reciente doctrina del Tribunal Constitucional contenida en las sentencias 119 y 136/2011, confirmada ésta en las sentencias 176/2011 y 209/2012, es que debe haber homogeneidad en las enmiendas, pero no en el contenido de las iniciativas legislativas. Hay que seguir insistiendo, por tanto, para que se amplíe el control de calidad de la ley y alcance a las iniciativas, sean de contenido homogéneo o heterogéneo.

En nuestra opinión, la libertad de configuración del legislador no es absoluta, porque ha de sujetarse a las exigencias de la seguridad jurídica. El propio Tribunal Constitucional ha señalado como límite a dicha libertad la interdicción de la arbitrariedad. El auto 72/2008, FJ 3, al afirmar que no resulta pertinente realizar un análisis a fondo de todas las motivaciones posibles de la norma y de todas sus eventuales consecuencias, recuerda que «también se ha destacado que no es posible confundir lo que es arbitrio legítimo del legislador con capricho, inconsecuencia o incoherencia creadores de desigualdad o distorsión en los efectos legales (por todas, STC 13/2007, de 18 de enero, FJ 4)».

La exigencia de claridad de la ley y coherencia del ordenamiento son aplicables tanto a las leyes de contenido homogéneo como a las leyes complejas, multisectoriales o transversales - por utilizar términos que aparecen en las sentencias comentadas- cuyos preceptos desde ya anunciamos que deben ir cohesionados por una finalidad.

El propio Tribunal Constitucional, al enjuiciar las enmiendas, se remite al «contenido definido por la iniciativa». Es imposible que este sirva de parámetro si la iniciativa carece de definición.

¿Qué elementos definen el contenido de las iniciativas legislativas? El Tribunal se refiere en la sentencia 119/2011 al debate de totalidad como determinante de su objeto y naturaleza ${ }^{79}$ : «sólo se enmienda lo ya definido» (FJ 6). Pero nos interesa aquí centrarnos en un momento temporal anterior, en el contenido de la propia iniciativa. Los elementos que la definen son el título — que pretende y debe dar noticia de ese contenido_-, la exposición de motivos cuya concurrencia exige para los proyectos de ley el artículo 88 de la Constitución, y, en su caso, la exposición del objeto y ámbito de aplicación de la norma que, según las Directrices de técnica normativa vigentes $\left(\mathrm{n}^{\circ} 18\right.$ y 19) debe figurar en las disposiciones generales de los anteproyectos de ley.

Pueden tomarse como base las palabras del Tribunal Constitucional cuando afirma que una ley de acompañamiento tiene un objeto «aunque heterogéneo, perfectamente delimitado en el momento de su presentación»(STC 136/2011 FJ9), o que la Constitución no impide al legislador dictar leyes complejas, multisectoriales, de contenido heterogéneo o transversales: ese contenido definido que insiste poseen las

79 F. SANTAOLALLA LÓPEZ, « ¿Es la homogeneidad material condición indispensable de las iniciativas legislativas?», cit., pág. 148, considera que este argumento no es incorrecto, pero sí débil si se tiene en cuenta que el debate de totalidad no existe en otros países y es una creación del Reglamento del Congreso, no de la Constitución, cuya desaparición por reforma recomienda. 
leyes de contenido heterogéneo tiene que existir, porque si no existe, entonces sí, debe reconocer que peligra la seguridad jurídica.

Tal vez con unos ejemplos gráficos se vea más claro: un proyecto de ley de medidas fiscales, administrativas y del orden social (iniciativa de contenido heterogéneo cuyo origen antes expuesto la concibe como norma de acompañamiento de la Ley de presupuestos) puede versar sobre un número amplio y variopinto de materias, cuya inclusión deberá motivar — valga la redundancia, para no excedernos con el término «justificar»— la exposición de motivos, como exige el artículo 88 de la Constitución. Pero quebraría ese contenido definido de la iniciativa si el Proyecto, al margen de su título y objeto, incluye — por poner un ejemplo ficticio — una modificación del Código Civil y de la Ley del Registro Civil para permitir alterar el orden de los apellidos.

Esta reforma parece que tampoco debería ser incluida en un Decreto-ley de medidas para combatir la pertinaz sequía o para reactivar la economía, que probablemente tengan también un contenido heterogéneo que debe estar conectado por su objeto o finalidad. Sólo en este caso puede hablarse con propiedad de leyes transversales, requeridas por la realidad política.

Hemos dado más arriba suficientes ejemplos que apoyan nuestra tesis: no son incongruentes, por más que duela a la técnica legislativa, las leyes transversales, tipo trasposición de directivas de servicios. Pero podrían serlo aquellos preceptos intrusos, aun en leyes de contenido heterogéneo, que crean una maraña normativa inextricable.

Podemos preguntarnos ¿vulnera esta posición la libertad de configuración del legislador? ¿Y en qué precepto constitucional encuentra apoyo? Creemos que el Tribunal podría adoptar en futuros pronunciamientos la línea argumental que hemos sostenido, que es la misma que la mantenida en la sentencia 119/2011 y posteriores respecto de las enmiendas - a mi modo de ver, incorrectamente fundamentada en el derecho de enmienda-, si toma como base el principio de seguridad jurídica, incluso el propio principio de publicidad de las normas, que como hemos dicho, no se identifica con la publicación de las leyes en el Boletín Oficial del Estado o de las iniciativas en el Boletín Oficial de las Cortes.

Esto le permitiría continuar admitiendo la constitucionalidad de las leyes de contenido heterogéneo, multisectoriales, transversales... siempre que los preceptos guarden al menos, parafraseando lo exigido respecto de las enmiendas por la sentencia 136/2011 FJ 8, una conexión flexible de homogeneidad que atienda a su funcionalidad, una conexión mínima, que no tiene que ser de identidad sino de afinidad material (STC 209/2012, FJ4). Lo que la misma sentencia, citando el auto 118/1999, aplica a las enmiendas: congruencia con «el objeto, espíritu y fines esenciales» de la iniciativa.

Han de excluirse por tanto las leyes y las iniciativa sin objeto determinado, amorfas, o en las que se incluyan —en la iniciativa o por vía de enmienda— preceptos intrusos que conviertan su contenido en indeterminado. Recordemos que el propio Tribunal afirma que la pluralidad de las materias sobre las que versa la iniciativa legislativa en las leyes de contenido heterogéneo no las convierte en leyes de contenido indeterminado (STC 136/2011, FJ 8).

Aquí cobra sentido todo lo afirmado por el Tribunal Constitucional sobre la congruencia de las enmiendas: los preceptos de la iniciativa tienen que ser congruentes entre sí, responder a su objeto, que puede ser — normalmente en detrimento de la se- 
guridad jurídica - múltiple, pero que tiene que existir: debe haber entre ellos ese lien, même indirect que exige a las enmiendas el artículo 45 de la Constitución francesa.

Hemos citado supra en el apartado III 1. b) varios ejemplos de preceptos intrusos. Tan perjudicial y lesivo para la calidad de la ley y la coherencia del ordenamiento resulta su inclusión por vía de enmienda como por la propia iniciativa legislativa. Son preceptos escondidos, de los que no da noticia el título de la ley ${ }^{80}$. Si el Tribunal se tomara la molestia de examinar las 89 normas modificadas por la Ley 50/1998, objeto de la sentencia 136/2011, tal vez encontrara alguno.

La clave no es el apriorismo sí o no a las leyes de contenido heterogéneo, es examinar caso por caso si hay preceptos incongruentes —el juicio del Tribunal tendrá que limitarse a los impugnados o unidos por conexión o consecuencia, art. 39.1 LOTC - incluso en leyes de contenido heterogéneo, que debe quedar definido en la iniciativa. Creo que, sin tener que modificar su reciente doctrina, puede luchar así contra la dispersión y oscuridad del ordenamiento, en aras de la seguridad jurídica. Y si no le basta este principio constitucional, que acuda al artículo 88 de la Constitución, con su exigencia de exposición de motivos y antecedentes necesarios para pronunciarse sobre los proyectos.

El propio Tribunal, como ya hemos señalado pero no nos cansamos de repetir, en la sentencia 209/2011, cuando analiza si unos preceptos introducidos por enmiendas guardan conexión material o no con la iniciativa (de la Ley de medidas de 2001), dice que su introducción es «congruente con su objeto, espíritu y fines esenciales (ATC 118/1999, de 10 de mayo, FJ 4), tanto más cuando la conexión reclamada no tiene que ser de identidad con las medidas previstas en el texto de la iniciativa sino de afinidad con las materias recogidas en el mismo» (FJ 4). Este mismo control flexible es el que podemos reclamar para las iniciativas de contenido heterogéneo ${ }^{81}$ : transversalidad no es arbitrariedad. Recordemos que en Alemania las reglas de técnica jurídica exigen una conexión objetiva a las leyes de artículos o de contenido variado (Mantelgesetze), el equivalente de nuestras leyes modificativas múltiples.

80 ¿Crea o no incertidumbre que el Real Decreto-ley 3/2013, de 22 de febrero, por el que se modifica el régimen de las tasas en el ámbito de la Administración de Justicia y el sistema de justicia gratuita, además de estas modificaciones — contenidas en los arts. 1, 2 y 3-, reforme la Ley de Enjuiciamiento Criminal para regular la destrucción de los efectos judiciales, en especial las drogas (art. 4), regule las cuotas de derechos pasivos y de las mutualidades de funcionarios en el mes de diciembre de 2012 (disposición adicional única) y en sus disposiciones finales modifique la Ley 17/2012, de Presupuestos Generales del Estado para 2013 (en tres cuestiones distintas: compensación de cuotas del impuesto de vehículos de tracción mecánica, cálculo de ingresos tributarios del Estado y endeudamiento de las entidades locales), aclare el régimen de los contratos de arrendamiento suscritos al amparo del Real Decreto-ley 27/2012 y modifique el Real Decreto-ley 10/2008 y la Ley 9/2012, en normas relativas a las sociedades de capital y entidades de crédito? Sabemos que el Tribunal Constitucional admite el contenido habitualmente heterogéneo de los Decretos-leyes, pero eso es una cosa, y otra que encubran sorpresas normativas inconexas con su objeto $\mathrm{y}$ finalidad.

81 F. SANTAOLALLA LÓPEZ, «¿Es la homogeneidad material condición indispensable de las iniciativas legislativas?», cit., págs. 169 y ss., reclama el control parlamentario interno de la congruencia material de las iniciativas, que compruebe una homogeneidad material mínima, defendiendo la inclusión en los Reglamentos de una referencia al contenido homogéneo que deben guardar los proyectos y proposiciones de ley. «Si se nos apura, resulta más lógico demandar esta homogeneidad y congruencia a las iniciativas legislativas principales que a las subsidiarias, pues de no ser así se hace muy difícil oponerse a las enmiendas inconexas». 
Estamos así poniendo el acento sobre la finalidad de la ley o de la iniciativa, aunque ésta sea multidireccional, finalidad que debe existir. Debe exigirse la transparencia en el objeto y en el contenido, expresada en la motivación, por imperativo de la seguridad jurídica y porque también lo exige el artículo 88 de la Constitución.

Frente a la oscuridad del ordenamiento, hemos de pedir transparencia e inteligibilidad de las leyes. En suma, seguridad jurídica. Animamos al Tribunal Constitucional a dar un paso más en la defensa de la Constitución, en lo que se refiere a la elaboración de las leyes y la técnica normativa. Si en las sentencias 136/2011 y 176/2011 no llegó a pronunciarse sobre los preceptos concretos incluidos por enmiendas en las leyes impugnadas, en otras leyes de contenido heterogéneo probablemente tenga ocasión de hacerlo, y también sobre los preceptos intrusos incluidos en las iniciativas.

Ojalá que el Alto Tribunal siga avanzando y depurando su doctrina en materia de técnica legislativa. El ordenamiento jurídico español se lo merece... y lo necesita.

\section{CONCLUSIÓN}

La conclusión va a ser muy breve, porque el último epígrafe recoge la posición a que nos ha conducido este trabajo.

Ha causado en la doctrina científica y en el ámbito técnico-parlamentario una impresión favorable la revisión de doctrina contenida en la STC 119/2011, que impone la homogeneidad de las enmiendas con el texto enmendado, bien que fundamentando este requisito no en el principio de seguridad jurídica, sino en el derecho de enmienda como parte integrante del ius in officium de los parlamentarios.

Casi a continuación, la esperanza de avance en el sendero hacia un ordenamiento jurídico más claro y congruente se desvanecía al admitir el Tribunal Constitucional en las sentencias 136/2011 y 176/2011 la constitucionalidad de las leyes de medidas fiscales, administrativas y del orden social —emblemáticas leyes de contenido heterogéneo- sobre la base de la libertad de configuración del legislador y de la ausencia de una norma constitucional que imponga la homogeneidad de las leyes — que sólo exige a las proposiciones de iniciativa popular su ley orgánica reguladora—, no invocando tampoco aquí la seguridad jurídica lesionada por la maraña normativa en que convierten al ordenamiento.

Creemos que en ambos casos — enmiendas y leyes de contenido heterógeneodebe tomarse este principio constitucional como punto de partida, reclamando en primer lugar las modificaciones reglamentarias precisas para dar cumplimiento a la STC 119/2011, que establezcan un control material de las enmiendas, y en segundo lugar —además de instando a que los Reglamentos parlamentarios introduzcan también la exigencia de homogeneidad de las iniciativas legislativas - animando al Tribunal Constitucional a que persevere, aun manteniendo la coherencia con su doctrina actual, en la exigencia de congruencia en el seno de las leyes, poniendo coto a los preceptos intrusos incluso en las leyes transversales o multisectoriales. 
TITLE: Relevancy of amendments, multisectorial laws, "riders» and "logrolling»: new decisions of the Spanish Constitutional Court.

ABSTRACT: Considering different decisions of the Spanish Constitucional Court on relevancy of amendtments to the Bill they aim at and on multisectorial laws, this paper, on the grounds of the constitutional rule of certainty of the law and with a view to the consistency of the legal system, defends the applicability of the principle of relevancy (from now on required to amendmentds) also to the contents of bills and laws, in avoidance of "logrolling» or inclusion of alien rules.

RESUMEN: Sobre la base del examen de la reciente doctrina revisada del Tribunal Constitucional sobre la homogeneidad de las enmiendas con el texto enmendado y de la admisión de la constitucionalidad del contenido beterogéneo de las leyes y las leyes ómnibus, el artículo propugna la aplicación del principio constitucional de seguridad jurídica para exigir la congruencia también en el seno de las leyes e iniciativas legislativas, poniendo coto a los preceptos intrusos incluso en las leyes transversales o multisectoriales.

Key Words: Constitutional decisions, Spanish Constitutional Court, legislative proceedings, legal drafting, amendments.

Palabras Clave: Tribunal Constitucional, procedimiento legislativo, ténica legislativa, elaboración de las leyes, leyes ómnibus, enmiendas.

FECHA DE RECEPCIÓN: 12.01.2013 FECHA DE ACEPTACIÓN: 12.02.2013 